\title{
Personalization in Game Design for Healthcare: a Literature Review on its Definitions and Effects
}

\author{
Marierose M.M. van Dooren ${ }^{1 *}$, Valentijn T. Visch ${ }^{1}$, Renske Spijkerman ${ }^{2}$, Richard \\ H.M. Goossens ${ }^{1}$, Vincent M. Hendriks ${ }^{2,3}$

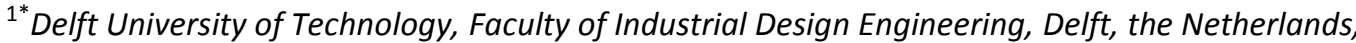 \\ \{M.M.M.vanDooren, V.T.Visch, R.H.M.Goossens\}@tudelft.nl \\ ${ }^{2}$ Parnassia Group, Brijder Addiction Care, Parnassia Addiction Research Centre (PARC), The Hague, \\ the Netherlands, \{Renske.Spijkerman, Vincent.Hendriks\}@brijder.nl \\ ${ }^{3}$ Curium, Leiden University Medical Centre, Department of Child and Adolescent Psychiatry, Leiden \\ University, Leiden, the Netherlands
}

\begin{abstract}
Personalization, the involvement of stakeholders in the design process, is often applied in serious game design for health. It is expected to enhance the alignment of a game to the preferences and capacities of the end-user, thereby increasing the enduser's motivation to interact with the game, which finally might enhance the aimedfor health effects of the game. However, the nature and effect of personalization have never been systematically studied, making assumptions regarding personalization ungrounded. In this literature review, we firstly provide a proposal of our Personalized Design Process-model, where personalization is defined as stakeholder involvement in the Problem Definition-, Product Design- and/or Tailoring Phase. Secondly, we conducted a systematic literature review on this model, focusing on health and its effects. In this review, 62 of the 2579 found studies were included. Analysis showed that a minority of the studies were of methodologically higher quality and some of these tested the health effect by contrasting tailored versus non-tailored games. Most studies involved stakeholders in the Tailoring Design Phase. Therefore, we conclude that involving stakeholders in the Tailoring Phase is valuable. However, to know if personalization is effective in the Product Design- and the Problem Definition Phase, more studies are needed.
\end{abstract}

Keywords: personalization; co-design; co-creation; tailoring; serious games; health

\section{Introduction}

Games are designed to motivate end-users to play. Especially in serious-games, that are typically a bit less entertaining than pure entertainment games, it is important for the game design to optimally engage the end-user. Research has suggested that involving stakeholders (like end-users and domain experts) in the design process enhances the engagement and motivation of the user to interact with the product [1] and consequently improves the game's implementation in the user's daily life. Such stakeholder involvement is often called co-design, where end-users are enabled to influence the design [2].

Currently, a lot of games for health are designed that involve "personalization", but clear and shared concepts of what personalization in game design entails are lacking. Besides, it is not sure if personalization contributes to the targeted health-effect of a game. Since theory on applying personalization in game design is lacking, we will use theory from personalized design methods and propose a theory on "Personalized Game Design". This "Personalized Game Design"(PDP)-model will be used to study if and how personalization in game design is effective in the context of health. Based on our PDP, we propose to define personalization as the involvement of stakeholders in at least one of the three PDP phases (Problem Definition-, Product Design- and Tailoring Phase). Stakeholders that can be involved across the phases of the PDP are: "designers", "domain experts" (therapist and care staff), "end-users" (typically patients), or "family/relatives" (of the patient). Some PDP phases are better suited to these four specific types of stakeholders than others. For example, designers and domain experts typically partake in the first Problem Definition Phase, by defining the problem and recommendations for focus of the design [3]. During the Product Design 
Phase, all stakeholders can contribute to provide design suggestions and feedback [4-6]. Finally, in the Tailoring Phase, the end-users are typically involved, for instance by selecting a personal avatar [7].

\subsection{Definitions of personalization}

Currently, many definitions are in use for the concept of personalization. In this section we first describe these concepts of personalization based on general design literature. This will be followed by our proposed PDP-model, consisting of three phases in the design process in which personalization can take place. These phases will be used to structure the literature results.

User-centered design process

Defined as: Any act during the design process where the user can be seen as a subject instead of a partner [8].

In user-centered design, the focus lies on designing for end-users [9] where these end-users have a passive role. Insights for designing a product are generated through interviews, observations and theory. An example of this is the design of an exercise game for older adults with help from focus groups and user testing [10]. A product is not created together with the user, but he or she only reflects on an idea, prototype, or is involved in the product's final user test [8]. Therefore, the user's influence on the product is limited.

\section{Co-creation process}

Defined as: Any act of collective creativity during design [8].

Co-creation builds on the tradition of user-centered design. The term 'co-creation' is often used interchangeably with 'co-design', although they have different definitions. Co-creation refers to a temporary exchange of ideas and experiences, and consists of "specific parts within the design process" [2].

\section{Co-design process}

Defined as: Any act during design in which users are considered as expert of their experiences.

Co-creation takes place within a co-design process, where the end-user "is given the position of 'expert of his/her experience' and plays a large role in developing knowledge, ideas and concepts" [8]. The designer facilitates the end-users, so they participate in a way that is most suitable to their abilities [8]. We have adopted the co-design definition of Mattelmäki and Sleeswijk Visser (2011), who viewed it as "a process and tools of collaborative engagement" [2]. The design responsibility is kept to the designers, because they are experts in design. It should be noted that co-design is also often called participatory design, as both concepts enable the end-users to influence the design [2]. However, with co-design a designer only wants to collaborate with end-users [2] and in participatory design, more weight is placed on end-user empowerment.

\section{Tailoring}

Defined as: The adaptation of the designed product by itself, by the end-users or by others.

If a user explicitly changes aspects of a product design, such as its esthetics, we propose the term "User Controlled Customization" [11]. End-users can thus partly determine the appearance or functionality of a product [12]. If a system tailors itself to the user and the behavior of the user, we term this "Use-Dependent Adaptation" $[11,13]$. In this case, the product changes while the user interacts with it, for example, by keeping the difficulty of the game aligned to the users' (health) improvements.

Mugge, Schoormans and Schifferstein (2009) found seven options for tailoring. In one option, the Mental Effort, users are creatively involved, for example, a do-it-yourself lamp that has a metal sheet which can be scratched to customize it [12]. These dimensions can generate different tailoring options for the product's design, of which some can be more or less favorable for specific target groups. Therefore, it is important to understand the target group and to know which of these dimensions are more or less favorable for the end-user.

Personalized Design Process

Defined as: Stakeholder involvement in Problem Definition, Product Design and Tailoring Phases of a product.

Common usage of "tailoring" and "personalization" is often non-consistent and can therefore be confusing. For example, some studies refer to individual characteristics (e.g., the name of the 
user) as personalization [14, 15] or as a tailoring variable [16] and some studies that saw personalization as a mechanism of tailoring $[14,17]$. We aim to avoid this confusion, by referring to the involvement of stakeholders across the design process as "personalization". We term this complete process, as the Personalized Design Process (PDP). As will be shown, personalization can take place at different phases in the PDP.

The PDP consists of three phases: Problem Definition, Product Design and Tailoring. In the Problem Definition Phase, information is generated by consulting stakeholders, in order to identify, establish and analyze the problem and generate related ideas. This sets the focus for the 'to-be designed' product, and can be seen as the basis for the whole design process [18]. The next Product Design Phase includes both Ideation and Embodiment. In Ideation, the first possible solutions are produced, resulting in product ideas or design proposal(s). In Embodiment, these are tested and evaluated by users, and further improved through iterations [19]. In the last Tailoring Phase, the final product can be tailored to the needs of individual end-users. Tailoring a product can be done by an end-user, others or automatically (see Figure 1), for example, in the case of the game's difficulty level automatically adapting to the user's skill level. In this review we do not differentiate between Ideation and Embodiment of the Product Design Phases because both consider the actual physical design of a product. The PDP thus consists of different phases in which stakeholders can be involved. The last phase is the Tailoring Phase, which consists of two types of Tailoring: "User Controlled Customization" and "Use-Depended Adaptation".

Although our model shows considerable overlap with earlier models that describe co-design processes and include stakeholder involvement in the Problem Definition- and Product Design Phase, it differs with regard to the Tailoring Phase, which is not present in these earlier models (e.g., $[8,20])$. For example, comparing our PDP with the process previously conceived by Zebeko and Tan [20], there is a large overlap between our Problem Definition and their Diagnostic phase, where information about an organization or community is collected, in order to understand the situation and challenges [20]. There is also an overlap between our Product Design Phase and their Design and Develop and Test phases, where the most appropriate stakeholders develop and prototype together [20]. However, our PDP goes further, by including a Tailoring Phase, to ensure that products are aligned to individual end-users within a target group. This is important, because, even in a coherent target group, there are always individual differences that need to be taken into account when designing a suitable product.

\subsection{Games for health}

Games are designed to be enjoyable and immersive, and can help to motivate or persuade end-users to continuing playing the game [21]. Games can also be used to facilitate the realization of healthoriented goals of the user (e.g., [22]). A main advantage of these kinds of game-interventions is that they are always available, compared to face-to-face interventions, and often effective in supporting health related changes of behaviors [23-25].

When designing games with stakeholders, the alignment of the game with the end-user's preferences, needs and competences can increase [8, 26, 27], which in turn can motivate the enduser to interact with the product [1, 28], thereby enhancing the persuasive feature of a product [29]. This is because stakeholders with different expertise (e.g., in design, the health context, or in their own preferences) have different point of views and can provide more complete insights into what the product should consists of and focus on. Stakeholder involvement in the design process of games is more likely to generate a health related transfer effect. Health related transfer effects are the effects a product is aiming to achieve, for example: effects on knowledge, mood, health, etc. Studies have focused on enhancing these transfer effects, by involving stakeholder in the design process [30, 31]. However, the effect of stakeholder involvement when designing games for health across the different phases of the PDP has not yet been studied in a systematic way. Therefore, this study aims to answer the following research question: How are Personalized Design Approaches applied in designing games for health, and how effective are they on health related outcomes?" 

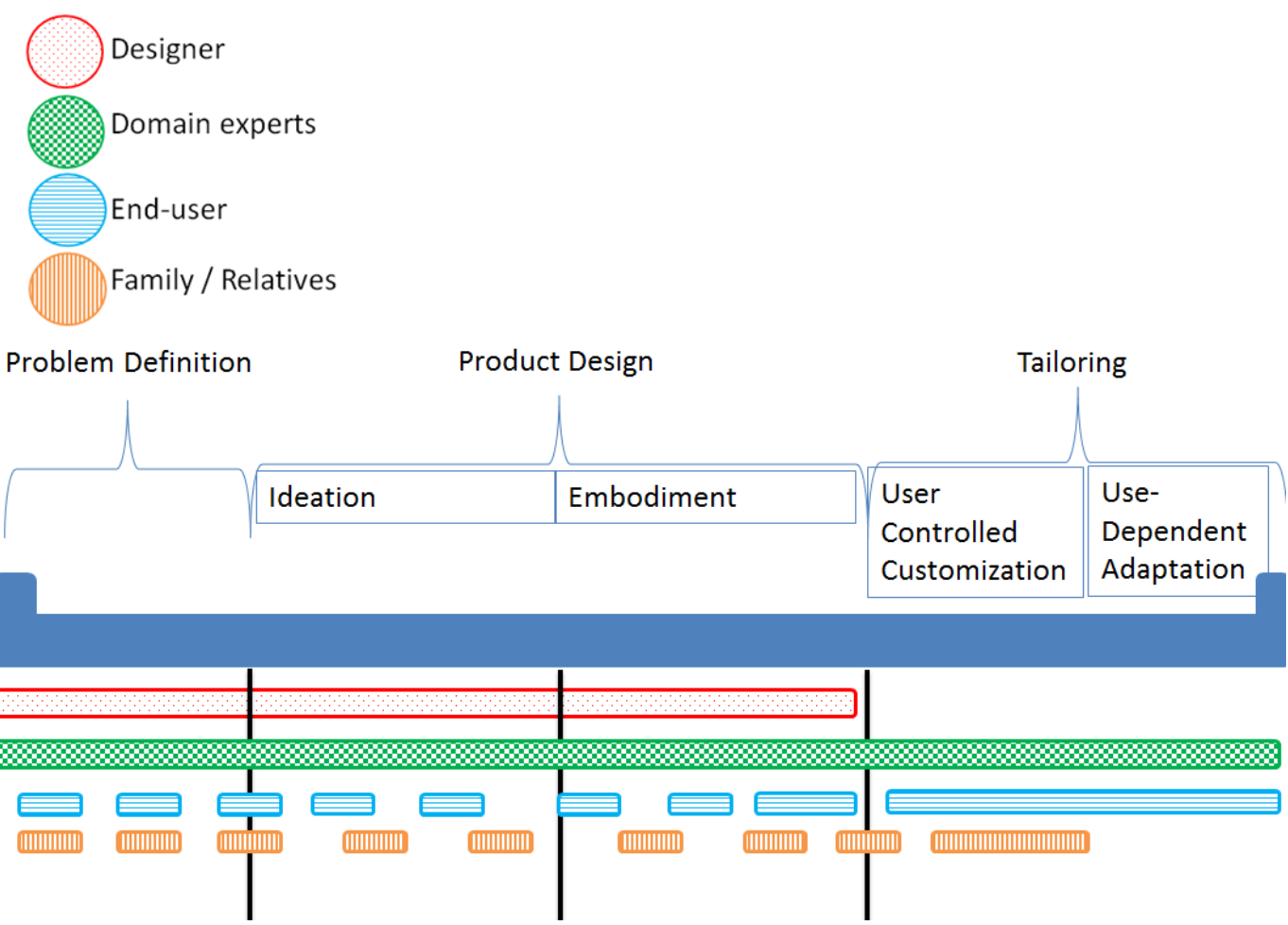

Figure 1. The three phases of the Personalized Design Process

\section{Methods}

In order to answer the research question, we conducted a literature study, with the aim of categorizing the design methods used in published empirical studies based on stakeholder involvement, as shown in Figure 1. We searched the following databases: IEE Inspec, ELSEVIER Scopus, Psychinfo, PubMed and Web of science. Keywords that served as basis for the search terms were divided into four groups: methodology, object, context of appliance and research method (see Table 1). Only empirical studies were included; the following types of articles were excluded: book reviews, technical studies, theoretical studies, reflections, reviews, withdrawn articles, editorials, studies with a focus on algorithms and articles not related to health. We first screened the abstracts and titles in order to deselect studies based on the exclusion criteria. The remaining articles were then scanned based on the inclusion/exclusion criteria in order to make a second selection. Lastly, we carefully analyzed the full texts of the remaining articles.

Table 1. Research keywords, divided in four groups.

\begin{tabular}{c|c|c|c|c}
\hline $\begin{array}{c}\text { A } \\
\text { Methodology }\end{array}$ & B Object (Games) & \multicolumn{2}{|c|}{ C Context of appliance (health) } & $\begin{array}{c}\text { D Research } \\
\text { method }\end{array}$ \\
\hline Co-creat* & Game* & Therapy & Behaviour & Experiment* \\
\hline cocreat* & Gami* & Disease & Illness & Random* \\
\hline Customi* & Persuasive & Health & Wellbeing & RCT \\
\hline Co-design* & & Care & Hospital & Evidence* \\
\hline Participatory & & Clinical & Training & Trial* \\
\hline Codesign* & & Disorder & Therapists & Empirical* \\
\hline Collaborat* & & Patient & Life & \\
\hline Co-develop* & & Medical & Health status & \\
\hline Codevelop* & & Psychology & Fitness & \\
\hline Co-product* & & Rehabilitation & Physical & \\
\hline
\end{tabular}




\begin{tabular}{c|c|c|c|c}
\hline Coproduct* & Physiologic* & Disease course & \\
\hline Personalize* & & Lifestyle & Health attitudes & \\
\hline Personalization & & Health Knowledge & Psychological & \\
\hline Personalise* & & Medicine & (behavio*) & \\
\hline Personalisation & & Telemedicine & & \\
\hline self-creat* & Treatment & & \\
\hline Self-made & & \multicolumn{2}{|c}{ disease management } & \\
\hline Self-product* & & \multicolumn{3}{|}{} \\
\hline
\end{tabular}

\section{Results of the literature review}

We retrieved literature from the abovementioned databases using the search terms in Table 1 from the start of electronic records until April 2015. This resulted in a total of 2579 papers: 705 studies from Web of Science, 497 of INSPEC, 704 of SCOPUS, 326 of Psychinfo and 347 of PUBMED. Of the 2579 papers, 62 were selected to determine how personalization approaches were adopted in research on game interventions for changing health related behavior. To answer the research question (How are Personalized Design Approaches applied in designing games for health, and how effective are they on health related outcomes?), we investigated in what way the reviewed studies involved the four stakeholders (designers, domain experts, end-users, and family / relatives of the end-users) in their design process. Because their involvement occurred in different PDP phases in the design process, we present their combinations. We first describe stakeholder involvement in the Problem Definition-, Product Design-, and Tailoring Phase separately, followed by the clustercombination of stakeholder involvement across the PDP phases. In 3.1 we discuss the stakeholder involvement, followed by the general healthcare and product effects in section 3.2. This is specified to stakeholder involvement across the PDP in section 3.3, which ends in a conclusion regarding the quality of the validation papers in 3.3.7. The closing section 3.4 describes the involved gameelements across the PDP.

\subsection{A general overview of papers involved in the Personalized Design Proces}

In this section, we describe stakeholder involvement in the different phases of the PDP (Problem Definition, Product Design (both Ideation and Embodiment) and Tailoring).

\subsubsection{Problem Definition}

Table 2. Stakeholder involvement in Problem Definition Phase.

\begin{tabular}{c|c|c|c}
\hline \multirow{2}{*}{} & \multicolumn{3}{|c}{ Problem Definition } \\
\cline { 2 - 4 } & $\mathbf{D}$ & $\mathbf{X}$ & $\mathbf{U}$ \\
\hline$[32]$ & $\mathrm{X}$ & & $\mathrm{X}$ \\
\hline$[33]$ & $\mathrm{X}$ & & $\mathrm{X}$ \\
\hline$[3]$ & $\mathrm{X}$ & $\mathrm{X}$ & \\
\hline
\end{tabular}

Footnote: $D=$ Designer; $X=$ Domain experts; $U=$ End-user

Three of the 62 studies involved stakeholders (designers, domain experts and end-users) only in the Problem Definition Phase, of which two studies involved both designers and end-users, but not domain experts [32, 33], and one involved designers and domain experts, but no end-users [3]. 


\subsubsection{Product Design}

Table 3. Stakeholder involvement in Product Design Phase.

\begin{tabular}{c|c|c|c|c|c|c|c}
\hline \multirow{2}{*}{} & \multicolumn{6}{c}{ Product Design } \\
\cline { 2 - 8 } & \multicolumn{5}{|c|}{ Ideation } & \multicolumn{3}{c}{ Embodiment } \\
\cline { 2 - 8 } & $\mathrm{D}$ & $\mathrm{X}$ & $\mathrm{U}$ & $\mathrm{F}$ & $\mathrm{D}$ & $\mathrm{X}$ & $\mathrm{U}$ \\
\hline$[34]$ & $\mathrm{X}$ & $\mathrm{X}$ & & & & & \\
\hline$[35]$ & & & $\mathrm{X}$ & & & & \\
\hline$[36]$ & $\mathrm{X}$ & $\mathrm{X}$ & $\mathrm{X}$ & $\mathrm{X}$ & $\mathrm{X}$ & $\mathrm{X}$ & $\mathrm{F}$ \\
\hline$[37]$ & $\mathrm{X}$ & $\mathrm{X}$ & & $\mathrm{X}$ & & & \\
\hline$[4]$ & $\mathrm{X}$ & & & & $\mathrm{X}$ & $\mathrm{X}$ & $\mathrm{X}$ \\
\hline
\end{tabular}

Footnote: $D=$ Designer $; X=$ Domain experts; $U=$ End-user $; F=$ Family

Five studies involved stakeholders in the Product Design Phase. Three of them only involved stakeholders in Ideation of the Product Design Phase, where a product was generated based on their comments, suggestions or guidelines [34, 35, 37]. Two other studies involved stakeholders in both Ideation and Embodiment of the Product Design Phase $[4,36]$. In the first study, designers were only involved in Ideation, where other stakeholders provided suggestions for improvement [4]. In the other study, components of a product were extensively pretested, and after the product was installed it was also previewed by others [36].

\subsubsection{Combining Problem Definition and Product Design}

Table 4. Stakeholder involvement in both Problem Definition- and Product Design Phase.

\begin{tabular}{c|c|c|c|c|c|c|c|c|c|c|c}
\hline \multirow{2}{*}{} & \multicolumn{3}{|c}{ Problem Definition } & \multicolumn{6}{c}{ Product Design } \\
\cline { 5 - 10 } & $\mathrm{D}$ & $\mathrm{X}$ & $\mathrm{U}$ & $\mathrm{F}$ & $\mathrm{D}$ & $\mathrm{X}$ & $\mathrm{U}$ & $\mathrm{F}$ & $\mathrm{D}$ & $\mathrm{X}$ & $\mathrm{U}$ \\
\hline$[38]$ & $\mathrm{X}$ & $\mathrm{X}$ & & & & & & & $\mathrm{X}$ & $\mathrm{X}$ & $\mathrm{X}$ \\
\hline$[39]$ & $\mathrm{X}$ & $\mathrm{X}$ & & & $\mathrm{X}$ & $\mathrm{X}$ & & & $\mathrm{X}$ & $\mathrm{X}$ & $\mathrm{X}$ \\
\hline$[40]$ & $\mathrm{X}$ & $\mathrm{X}$ & & & & & & & $\mathrm{X}$ & $\mathrm{X}$ & $\mathrm{X}$ \\
\hline$[41]$ & $\mathrm{X}$ & $\mathrm{X}$ & $\mathrm{X}$ & & & & & & $\mathrm{X}$ & $\mathrm{X}$ & $\mathrm{X}$ \\
\hline$[42]$ & $\mathrm{X}$ & $\mathrm{X}$ & $\mathrm{X}$ & $\mathrm{X}$ & & & & & $\mathrm{X}$ & $\mathrm{X}$ & \\
\hline$[5]$ & $\mathrm{X}$ & $\mathrm{X}$ & & & $\mathrm{X}$ & $\mathrm{X}$ & & & & & \\
\hline$[6]$ & $\mathrm{X}$ & $\mathrm{X}$ & $\mathrm{X}$ & & $\mathrm{X}$ & $\mathrm{X}$ & & & & & \\
\hline$[43]$ & $\mathrm{X}$ & $\mathrm{X}$ & $\mathrm{X}$ & $\mathrm{X}$ & $\mathrm{X}$ & $\mathrm{X}$ & $\mathrm{X}$ & & $\mathrm{X}$ & $\mathrm{X}$ & $\mathrm{X}$ \\
\hline
\end{tabular}

Of the 62 studies, eight studies involved domain experts during both the Problem Definitionand Product Design Phase. Four studies involved mainly designers and domain experts as stakeholders in the Problem Definition Phase and designers, domain experts and end-users in Embodiment of the Product Design Phase [38, 40-42], for example, by observing end-users and giving cultural probes (ambiguous stimuli and assignments that bring inspiration to design) to domain experts and relatives [42]. Two other studies included stakeholders, mainly designers and domain experts, in the Problem Definition Phase and Ideation of the Product Design Phase [5, 6], by letting end-users test game scenarios that were designed by domain experts and designers. Lastly, two studies involved stakeholders in Problem Definition Phase and Ideation and Embodiment of Product Design Phase [39, 43]. 


\subsubsection{Tailoring}

Table 5. Stakeholder involvement in Tailoring Phase.

\begin{tabular}{|c|c|c|c|c|c|c|c|}
\hline & \multicolumn{7}{|c|}{ Tailoring } \\
\hline & \multicolumn{5}{|c|}{ User Controlled Customization } & \multicolumn{2}{|c|}{ Use-Dependent Adaptation } \\
\hline & \multicolumn{2}{|c|}{ Task } & \multicolumn{3}{|c|}{ Virtual self } & Task & $\begin{array}{c}\text { Virtual/feedback/ } \\
\text { textual }\end{array}$ \\
\hline & $\mathbf{S}$ & 3 & $\mathbf{I}$ & $\mathbf{R}$ & $\mathbf{X}$ & & \\
\hline [44] & & & & & $\mathrm{X}$ & & \\
\hline [45] & & $\mathrm{X}$ & & & & & \\
\hline [46] & & & & & $\mathrm{X}$ & & \\
\hline [47] & & $\mathrm{X}$ & & & & & \\
\hline$[7]$ & & & $\mathrm{X}$ & $\mathrm{X}$ & & & \\
\hline [48] & & $\mathrm{X}$ & & & & & \\
\hline [49] & & & $\mathrm{X}$ & $\mathrm{X}$ & & & \\
\hline$[50]$ & & $\mathrm{X}$ & & & & & \\
\hline [51] & & & & & $\mathrm{X}$ & & \\
\hline [52] & & & & & & $X$ & \\
\hline [53] & & & & & & X & \\
\hline [54] & & & & & & $X$ & $X$ \\
\hline [55] & & & & & & $X$ & $X$ \\
\hline$[56]$ & & & & & & & $\mathrm{X}$ \\
\hline [57] & & & & & & & $\mathrm{X}$ \\
\hline [58] & & & & & & & $X$ \\
\hline [59] & & & & & & & $\mathrm{X}$ \\
\hline$[60]$ & & & & & & & $\mathrm{X}$ \\
\hline [61] & & & & & & $\mathrm{X}$ & $\mathrm{X}$ \\
\hline [62] & $\mathrm{X}$ & & & & & $\mathrm{X}$ & \\
\hline [63] & $X$ & & & & & $X$ & \\
\hline [64] & $\mathrm{X}$ & & & & & X X & \\
\hline$[65]$ & $\mathrm{X}$ & & & & & $X$ & \\
\hline [66] & $\mathrm{X}$ & & & & & $\mathrm{X}$ & \\
\hline [67] & $X$ & & & & & $X$ & $X$ \\
\hline [68] & $X$ & & & & & $X$ & $X$ \\
\hline [69] & & $X$ & & & & & $X$ \\
\hline [70] & & $X$ & & & & & $X$ \\
\hline [71] & & $\mathrm{X}$ & & & & $X$ & $X$ \\
\hline [72] & & $X$ & & & & & $X$ \\
\hline
\end{tabular}

Footnote; I=ideal; $R=$ real/realistic; $x=$ ideal/real; $S=$ self; $3=$ third person

With "Use-Dependent Adaptation", a Kinect device was often used to give visual tailored feedback about the performance or remaining time the end-user had [55-61] and/or by tailoring the difficulty of the tasks to end-user input, like performance [52-54]. In "User Controlled Customization", end-users tailored avatars that could represent an idealized self or actual self 
[7, 44, 49, 51, 49] and others defined the objectives, difficulty level or specified the stimuli of a product $[45,47,48,50]$.

Eleven studies involved both Tailoring types, where the end-users provided input used in combination with giving tailored visual performance feedback [67, 68], giving feedback based on the name of an end-user [62,63], or by adapting the difficulty level based on information provided by a user beforehand, e.g., through baseline measurements [64-66]. However, others (mostly domain experts) could also tailor, by defining objectives and difficulty levels, which was combined with giving automatic feedback about performance [70-72].

\subsubsection{Combinations of Problem Definition, Product Design and Tailoring}

Table 6. Stakeholder involvement in Problem Definition, Product Design and Tailoring Phase.

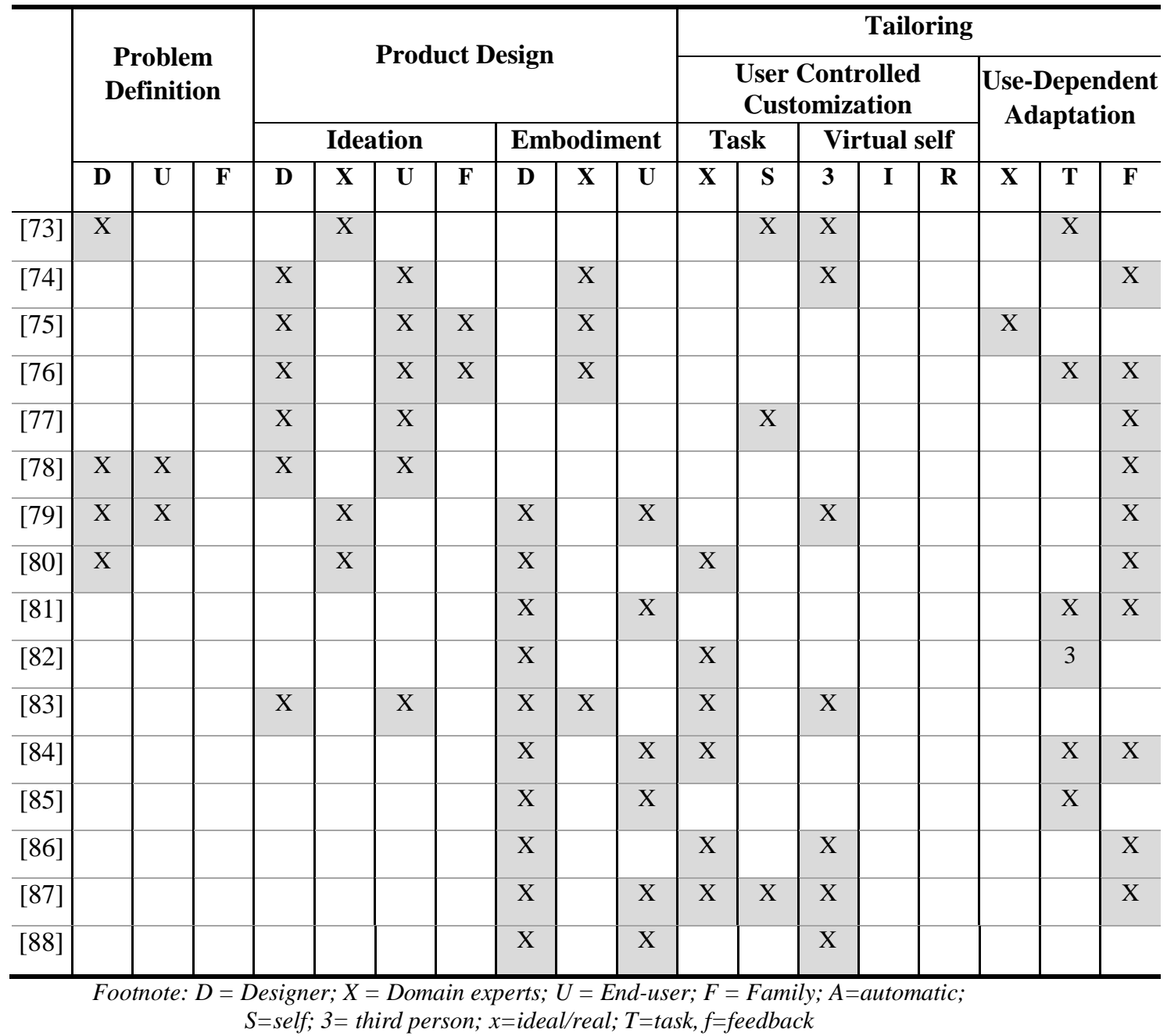

Of the 62 studies, seven involved stakeholders in the Embodiment of Product Design- and Tailoring Phase. The studies were mainly conducted in the domains of rehabilitation and physical health [81, 84, 85, 87, 88]. In one study, end-users with Autism Spectrum Disorders (ASD) played a therapy game with a robot, of which the behavioral and experience results were used to improve the next the experiment by domain and robotic experts [83]. Four studies involved stakeholders (mainly endusers and/or domain experts) in Ideation of the Product Design Phase and Tailoring Phase. One study used earlier guidelines that were combined with interviews and evaluations with end-users [77]. Involving stakeholders in both the Tailoring- and the Product Design Phase was thus quite common, however involving end-users in Ideation was least commonly combined with the Tailoring Phase. Only three studies involved stakeholders in all the phases; these focused on physical health [78], mental health care $[79,80]$, and/or where parents or domain experts could tailor the tool $[78,79]$. 


\subsection{Overview healthcare and product effects}

Studies involving stakeholders in the PDP have mainly focused on teaching end-users about health related topics [6, 32-36, 39, 43], aiming at behavioral change or adherence [3, 5, 7, 38, 40-42, 45, $48,49,52,54-58,60-62,64-74,77,78,81-88]$, or at attitudinal change $[4,37,44,46,47,50,51,53$, $59,63,75,76,79,80]$. Currently, researchers are optimistic that personalized games in a health context will generate a positive influence on interaction experience, interaction behavior and health related transfer effects. Interaction experience focusses on the subjective experience individuals have when interacting with a product $[89,90]$ and consists of experiences regarding aesthetics, meaning and emotions [90], for example, when the end-user likes the appearance of a product. The focus of interaction behavior lies on all forms of end-user behavior when the end-user interacts with the product, for example, on forming, altering or reinforcing self-initiated behavior [91]. For example, if and how easy it is to use the product. Lastly, health related transfer effects are the effects on "forming, altering, or reinforcing user-compliance, -behavior, or -attitude", and can be regarded as a transfer effect of game-world related experiences to a user's subsequent behavior in the real-world (c.f., [21] for a theoretical model of experience effects). Health related transfer effects thus reflects the intended behavioral change of the end-user in the daily life of the end-user, e.g., the compliance of an end-user to the medication schedule [92-94] or enhancing daily physical activity [21]. However, the optimism that these aspects are positively influenced, is not supported by a great deal of evidence.

The effects of the studies, combined with stakeholder involvement across the PDP are described below in more detail where we evaluate the effects on interaction experience, interaction behavior and health related transfer effects. Studies in this literature review focus on either one, a combination of, or all three of these outcome variables and of the 62 reviewed studies, a majority $(\mathrm{N}=46)$ focused on interaction experiences. The following five aspects were used to rate the methodological quality of the studies: pre-post measurement, comparison or control group, (blind) randomization, number of participants and valid and reliable measurements. A higher methodological quality means that at least a comparison or control group was present in the paper. Most studies included small samples ( 25 or less participants), and, hence, had insufficient statistical power to draw firm conclusions about the effects of involving stakeholders in the PDP. A majority of the studies generated information about interaction experiences, by using questionnaires $(N=24)$, interviews $(N=17)$ or observations (e.g., to see the end-users' facial expressions while interacting with the product) $(\mathrm{N}=13)$. A total of 28 studies focused on interaction behavior, often measured by observations $(\mathrm{N}=15)$ or by using hardware data derived from the tool itself $(\mathrm{N}=14)$. A total of 40 studies focused on health related transfer effects, which was often assessed by questionnaires and tests $(\mathrm{N}=26)$ and sometimes by physiological measures (e.g., heart rate) $(\mathrm{N}=7)$. In general, data was obtained at pre-post $[36,40$, $52,62,79]$ or during and after interaction with the product $[44,53]$. Because the duration of the studies were heterogeneous $[45,54,73,83]$, it is hard to compare these results. A minority of the studies used a control group $(\mathrm{N}=17)$, of which eight had small to average study samples, ranging from 8 to 57 participants, and five had large study samples, ranging from 95 to 121 participants. A total of 9 studies randomly assigned their participants to either the control or experimental group [7, $49,57,61,63,65,74,79,86]$. When measuring the effect of a product, experimental groups are compared with control groups. Ideally, both groups are equal except for the independent variable (e.g., when comparing a product with a tailored product, and the only difference is the tailoring). This would make it possible to draw conclusions on the effect of the independent variable [95]. Because validation research in the context of games for health is limited, we not only took into account the control groups that received a non-personalized game, but also treatment as usual (e.g., no game-intervention), or control groups that consisted of other user-groups (e.g., healthy end-users $[38,42])$. There are many different methods for measuring study quality. As game research is a young and developing domain, we did not use these, since applying a strict index is not appropriate. A minority of the studies in this review involved a randomized controlled design, and a majority of the studies used qualitative measurements including a small sample size. In addition, the results were mostly founded on outcomes of questionnaires that were not validated. This means that if a questionnaire is not validated, it is unclear if it measures what it claims to measure. Both qualitative measures and small sample size indicate a 'low quality' ranking of the studies included in this review. 


\subsection{Combining the healthcare effects with the Personalized Design Process}

This section focusses on the healthcare effects of studies that involved stakeholders in the PDP. The tables consist of a) Problem Definition- or Product Design Phase only, followed by b) both Problem Definition- and Product Design Phase, c) either User Controlled Customization or Use-Dependent Adaptation of the Tailoring Phase, d) both types of the Tailoring Phase, e) combining Product Design and Tailoring Phases, and lastly f) other combination of phases. No study reported a power-analysis.

\subsubsection{Studies which involved stakeholders only in either the Problem Definition or Product Design Phase}

Table 7. Characteristics to analyze the quality of studies involved in Problem Definition Phase.

\begin{tabular}{c|c|c|c|c|c}
\hline & \multicolumn{2}{|c|}{$\begin{array}{c}\text { Pre-post } \\
\text { measurement }\end{array}$} & $\begin{array}{c}\text { Number of } \\
\text { participant }\end{array}$ & \multicolumn{2}{c}{ Valid and reliable measurements } \\
\hline & Yes & No & N & Yes & No \\
\hline$[32]$ & $\mathrm{X}$ & & 807 & & $\mathrm{X}$ \\
\hline$[33]$ & $\mathrm{X}$ & & 23 & $\mathrm{X}$ & $\mathrm{X}$ \\
\hline$[3]$ & & $\mathrm{X}$ & 5 & & $\mathrm{X}$ \\
\hline
\end{tabular}

Studies that involved stakeholders in the Problem Definition Phase were of low methodological quality. Results suggested improvements regarding knowledge and awareness about health, more specifically regarding (raw) milk and HIV, which could lead to behavioral changes [32, 33]. A gradual need to collaborate and enhanced social interaction was found in end-users involved in collaboration sessions with a multi-touch game [3], beneficial to the health problem in question.

Table 8. Characteristics to analyze the quality of studies involved in Product Design Phase.

\begin{tabular}{r|c|c|c|c|c}
\hline & \multicolumn{2}{|c|}{$\begin{array}{c}\text { Pre-post } \\
\text { measurement }\end{array}$} & $\begin{array}{c}\text { Number of } \\
\text { participants }\end{array}$ & \multicolumn{2}{|c}{ Valid and reliable measurements } \\
\hline & Yes & No & N & Yes & No \\
\hline$[34]$ & $X$ & 33 & & $X$ \\
\hline$[35]$ & $X$ & & 41 & & $X$ \\
\hline$[36]$ & $X$ & & 3829 & $X$ & \\
\hline$[37]$ & $X$ & & 4 & & $X$ \\
\hline$[4]$ & & $X$ & 45 & & $X$ \\
\hline
\end{tabular}

Studies that involved stakeholders in the Product Design Phase were of low methodological quality. Results suggested enhanced knowledge about health (e.g., about AIDS) [35, 36]. A study that focused on discussions regarding obesity suggested a doubled discussion time between domain experts, end-users and family, and improved self-efficacy of domain experts in doing this [34]. Other enhancements were found in social interaction and communication, combined with less stereotype behavior in a child with an ASD [37]. Lastly, feedback from end-users suggested that a product was feasible and acceptable with regard to what it aimed to achieve [4].

\subsubsection{Studies which involved stakeholders in both the Problem Definition and Product Design Phases}

Table 9. Characteristics to analyse the quality of studies involved in Problem Definition- and Product Design Phase.

\begin{tabular}{c|c|c|c|c|c|c|c}
\hline & \multicolumn{2}{|c|}{$\begin{array}{c}\text { Pre-post } \\
\text { measurement }\end{array}$} & \multicolumn{2}{c|}{$\begin{array}{c}\text { Comparison or } \\
\text { control group }\end{array}$} & $\begin{array}{c}\text { Number of } \\
\text { participants }\end{array}$ & \multicolumn{2}{|c}{$\begin{array}{c}\text { Valid and reliable } \\
\text { measurements }\end{array}$} \\
\hline & Yes & No & Yes & No & N & Yes & No \\
\hline$[38]$ & & $\mathrm{X}$ & $\mathrm{X}$ & & $?$ & & $\mathrm{X}$ \\
\hline
\end{tabular}




\begin{tabular}{c|c|c|c|c|c|c|c}
\hline$[39]$ & & $\mathrm{X}$ & $\mathrm{X}$ & & $53 \& 36$ & & $\mathrm{X}$ \\
\hline$[40]$ & $\mathrm{X}$ & & & $\mathrm{X}$ & 5 & $\mathrm{X}$ & $\mathrm{X}$ \\
\hline$[41]$ & $\mathrm{X}$ & & & $\mathrm{X}$ & 5 & $\mathrm{X}$ & $\mathrm{X}$ \\
\hline$[42]$ & & $\mathrm{X}$ & & $\mathrm{X}$ & 10 & $\mathrm{X}$ & $\mathrm{X}$ \\
\hline$[6]$ & & $\mathrm{X}$ & & $\mathrm{X}$ & 4 & & $\mathrm{X}$ \\
\hline$[43]$ & $\mathrm{X}$ & & & $\mathrm{X}$ & 165 & & $\mathrm{X}$ \\
\hline$[5]$ & $\mathrm{X}$ & $\mathrm{X}$ & & $\mathrm{X}$ & 14 & $\mathrm{X}$ & $\mathrm{X}$ \\
\hline
\end{tabular}

Most studies that involved stakeholders in both the Problem Definition- and Product Design Phase had methodological limitations. For example, only two studies had a control group [38, 39], most studies had a general low number of participants (5 studies involved between 4 and 14) and a minority of the studies applied validated and reliable measurements, e.g., used observational data. Results of the studies showed that due to the games, end-users improved in various outcomes measurements, like their physical health. Examples regarding the improvements that were found on physical health, were some improvements in shoulder muscle activity [41] and in motivated participants that played the game often, of which one even improved movements and use of the impaired limb [40]. Other results showed that end-users improved their knowledge regarding diabetes [6], cardiopulmonary resuscitation [39], and obesity and nutrition [43]. Significant correlations were found between physiological responses to stressful experiences and subjective evaluations on stress in PTSS (Post-Traumatic Stress Syndrome) patients, and a clear correlation between diagnostic PTSD severity and skin conductance responses [5], which could be important for stress inoculation training. End-users with ASD and healthy controls matched on IQ, gender and age, showed difficulties in respecting the personal space of virtual others, but acknowledged that behaving in a virtual environment was different from daily life [38]. Lastly, in a study where endusers participated with both a game and a traditional leisure activity product, results suggested that some participants improved social behavior during sessions with the game, but that the control product made the user answer more questions in sentences and handle the object more [42].

\subsubsection{Studies which involved stakeholders in either User Controlled Customization or Use-Dependent Adaptation of the Tailoring Phase}

Table 10. Characteristics to analyse the quality of studies involved in User Controlled Customization.

\begin{tabular}{c|c|c|c|c|c|c|c|c|c}
\hline & \multicolumn{2}{|c|}{$\begin{array}{c}\text { Pre-post } \\
\text { measurement }\end{array}$} & \multicolumn{2}{c|}{$\begin{array}{c}\text { Comparison } \\
\text { or control } \\
\text { group }\end{array}$} & \multicolumn{2}{c|}{$\begin{array}{c}\text { (blind) } \\
\text { randomization }\end{array}$} & \multicolumn{2}{c|}{$\begin{array}{c}\text { Number of } \\
\text { participants }\end{array}$} & \multicolumn{2}{c}{$\begin{array}{c}\text { Valid andreliable } \\
\text { measurements }\end{array}$} \\
\hline$[44]$ & Yes & No & Yes & No & Yes & No & N & Yes & No \\
\hline$[45]$ & $\mathrm{X}$ & $\mathrm{X}$ & & $\mathrm{X}$ & & $\mathrm{X}$ & 12 & $\mathrm{X}$ & $\mathrm{X}$ \\
\hline$[46]$ & & $\mathrm{X}$ & & $\mathrm{X}$ & & $\mathrm{X}$ & $? ?$ & & $\mathrm{X}$ \\
\hline$[47]$ & $\mathrm{X}$ & & $\mathrm{X}$ & & & $\mathrm{X}$ & 40 & $\mathrm{X}$ & \\
\hline$[7]$ & & $\mathrm{X}$ & $\mathrm{X}$ & & $\mathrm{X}$ & & 130 & $\mathrm{X}$ & $\mathrm{X}$ \\
\hline$[48]$ & $\mathrm{X}$ & & $\mathrm{X}$ & & & $\mathrm{X}$ & 8 & & $\mathrm{X}$ \\
\hline$[49]$ & $\mathrm{X}$ & & $\mathrm{X}$ & & $\mathrm{X}$ & & 95 & $\mathrm{X}$ & $\mathrm{X}$ \\
\hline$[50]$ & & $\mathrm{X}$ & & $\mathrm{X}$ & & $\mathrm{X}$ & $>200$ & & $\mathrm{X}$ \\
\hline$[51]$ & & $\mathrm{X}$ & & $\mathrm{X}$ & & $\mathrm{X}$ & 2 & & $\mathrm{X}$ \\
\hline
\end{tabular}


Studies that involved stakeholders in User Controlled Customization had limited methodological weaknesses. The studies were effective with regard to various outcomes measurements. One study indicated that end-users showed physiological indicators (by levels of skin conductance) of emotions during gameplay, and that they had the feeling they were part of the game [44]. Besides, end-users were more motivated to play, and experienced feelings of competition and understandability of the product [50], and showed behaviors and experiences on cooperation and playability [46]. Feelings of togetherness and mental stimulation were enhanced in a virtual environment [51], as well as a reduced agitation and improved mood during an intervention with Alzheimer patients compared to controls [47]. End-users that participated in all conditions had more social behaviors in "enforced collaboration" than in "free play" [45]. Studies with control conditions reported end-users being more "aggressive" after playing a violent game with a customized avatar compared to a non-violent game and generic avatar [7]; they also found that an ideal-self avatar significantly influenced prevention-focused behavior to keep this ideal appearance in real life, but an "actual self" was related to promotion- focused behavior [49]. Lastly, results suggested that controls had significantly higher progression on cognitive functions compared to the experimental group [48].

Table 11. Characteristics to analyse the quality of studies involved in Use-Dependent Adaptation.

\begin{tabular}{c|c|c|c|c|c|c|c|c|c}
\hline & \multicolumn{2}{|c|}{$\begin{array}{c}\text { Pre-post } \\
\text { measurement }\end{array}$} & \multicolumn{2}{c|}{$\begin{array}{c}\text { Comparison or } \\
\text { control group }\end{array}$} & \multicolumn{2}{c|}{$\begin{array}{c}\text { (blind) } \\
\text { randomization }\end{array}$} & $\begin{array}{c}\text { Number of } \\
\text { participants }\end{array}$ & \multicolumn{2}{c}{$\begin{array}{c}\text { Valid and } \\
\text { reliable } \\
\text { measurements }\end{array}$} \\
\hline$[52]$ & $\mathrm{X}$ & & & $\mathrm{X}$ & & $\mathrm{X}$ & 2 & $\mathrm{X}$ & $\mathrm{X}$ \\
\hline$[53]$ & & $\mathrm{X}$ & & $\mathrm{X}$ & & $\mathrm{X}$ & $6 \& 5$ & & $\mathrm{X}$ \\
\hline$[54]$ & $\mathrm{X}$ & $\mathrm{X}$ & $\mathrm{X}$ & & & $\mathrm{X}$ & $21 \& 20$ & $\mathrm{X}$ & $\mathrm{X}$ \\
\hline$[55]$ & $\mathrm{X}$ & $\mathrm{X}$ & & $\mathrm{X}$ & $\mathrm{X}$ & & 19 & $\mathrm{X}$ & $\mathrm{X}$ \\
\hline$[56]$ & $\mathrm{X}$ & & & $\mathrm{X}$ & & $\mathrm{X}$ & 6 & $\mathrm{X}$ & Yes \\
\hline$[57]$ & & $\mathrm{X}$ & $\mathrm{X}$ & & $\mathrm{X}$ & & 8 & & $\mathrm{X}$ \\
\hline$[58]$ & $\mathrm{X}$ & & & $\mathrm{X}$ & & $\mathrm{X}$ & 6 & & $\mathrm{X}$ \\
\hline$[59]$ & & $\mathrm{X}$ & & $\mathrm{X}$ & & $\mathrm{X}$ & 14 & & $\mathrm{X}$ \\
\hline$[60]$ & $\mathrm{X}$ & & & $\mathrm{X}$ & & $\mathrm{X}$ & 16 & $\mathrm{X}$ & $\mathrm{X}$ \\
\hline$[61]$ & $\mathrm{X}$ & & $\mathrm{X}$ & & $\mathrm{X}$ & & $37 \& 34$ & $\mathrm{X}$ & \\
\hline
\end{tabular}

Studies that involved stakeholders in Use-Dependent Adaptation also had some methodological flaws and were effective with regard to various outcomes measurements. For example, two studies suggested that the users had positive subjective experiences while playing the game (e.g., enjoyment and a sense of accomplishment) and that they were motivated by the tailoring aspect of the activity [53, 59]. Regarding physical health, the physical performance improved significantly [60], which was a significant [52] or a percentage improvement in motor and sensory impairments [56]. End-users that participated in both conditions rated the experimental game as more enjoyable [55], and after playing an imitative collaborative game with a robot, children with ASD played more with each other [58]. Studies with a control group found significant improvements in symptoms and balance functions, with longer in-patient stay in the control condition [61] and that a product was usable, acceptable and it offered personalized arm-training [54]. A study that only focused on the experimental group, found that a majority increased their health awareness, connection with the nurse, but also experienced use frustration [57]. 


\subsubsection{Studies which involved stakeholders in both Use-Dependent Adaptation and User Controlled Customization of the Tailoring Phase}

Table 12. Characteristics to analyse the quality of studies in both types of the Tailoring Phase.

\begin{tabular}{|c|c|c|c|c|c|c|c|c|c|}
\hline & \multicolumn{2}{|c|}{$\begin{array}{c}\text { Pre-post } \\
\text { measurement }\end{array}$} & \multicolumn{2}{|c|}{$\begin{array}{c}\text { Comparison } \\
\text { or control } \\
\text { group } \\
\end{array}$} & \multicolumn{2}{|c|}{$\begin{array}{l}\text { (blind) } \\
\text { randomization }\end{array}$} & \multirow{2}{*}{$\begin{array}{c}\begin{array}{c}\text { Number of } \\
\text { participants }\end{array} \\
\mathbf{N}\end{array}$} & \multicolumn{2}{|c|}{$\begin{array}{c}\text { Valid and reliable } \\
\text { measurements }\end{array}$} \\
\hline & Yes & No & Yes & No & Yes & No & & Yes & No \\
\hline$[62]$ & $\mathrm{X}$ & & & X & & $\mathrm{X}$ & 23 & $\mathrm{X}$ & $\mathrm{X}$ \\
\hline [63] & $\mathrm{X}$ & & $\mathrm{X}$ & & $\mathrm{X}$ & & $57 \& 15$ & $\mathrm{X}$ & \\
\hline [64] & & $\mathrm{X}$ & & $\mathrm{X}$ & & $\mathrm{X}$ & 10 & & $\mathrm{X}$ \\
\hline [65] & $\mathrm{X}$ & & $\mathrm{X}$ & & $\mathrm{X}$ & & 155 & $\mathrm{X}$ & \\
\hline [66] & & $\mathrm{X}$ & & $\mathrm{X}$ & & $\mathrm{X}$ & 30 & & $\mathrm{X}$ \\
\hline [67] & $\mathrm{X}$ & $\mathrm{X}$ & & $\mathrm{X}$ & & $\mathrm{X}$ & 17 & $\mathrm{X}$ & \\
\hline [68] & $\mathrm{X}$ & & $\mathrm{X}$ & & & $\mathrm{X}$ & $19 \& 17$ & $\mathrm{X}$ & $\mathrm{X}$ \\
\hline [69] & $\mathrm{X}$ & & & $\mathrm{X}$ & & $\mathrm{X}$ & 9 & $X$ & $\mathrm{X}$ \\
\hline [70] & & $\mathrm{X}$ & & $\mathrm{X}$ & & $\mathrm{X}$ & 9 or 8 & & $\mathrm{X}$ \\
\hline [71] & $\mathrm{X}$ & & & $\mathrm{X}$ & & $\mathrm{X}$ & 15 & $\mathrm{X}$ & \\
\hline [72] & $\mathrm{X}$ & & & $\mathrm{X}$ & & $\mathrm{X}$ & 3 & $\mathrm{X}$ & $\mathrm{X}$ \\
\hline
\end{tabular}

Studies that involved stakeholders in both types of the Tailoring Phase had some methodological flaws. Results suggested positive results with regard to various outcome measures, like positive experiences while interacting with the product, sometimes with suggestions for improvement (e.g., worries of falling while using the product) $[66,67,70]$. Physical health was positively influenced (e.g., postural stability) [71, 72]. A study that focused on smoking cessation, showed that at followup only $14.3 \%$ of the end-users had not smoked in the past 7 days, and that product use declined over time [62]. Two studies let end-users participate in all conditions, which resulted in a longer playing-time than allocated, higher than expected speech improvements compared to natural conversation [69], and that healthy end-users significantly increased successful pointing tasks and challenged experiences in the tailored session, compared to random adaptation but without differences in experiences (difficulty, frustration and fatigue) in a post-stroke therapy game [64]. Studies with a control group found significant effects in the intervention group regarding a decrease in fat mass, weight and BMI (Body Mass Index), [68], better arithmetic skills, higher intrinsic motivation, feelings of self-competency and attention [63], and enhancement in all 8 domains of cognitive performances compared to 4 in adherence only, or 6 in intent-to-treat of the control group [65].

\subsubsection{Combining the Product Design and Tailoring Phase}

Table 13. Characteristics to analyse the quality of studies in Product Design and Tailoring Phase.

\begin{tabular}{c|c|c|c|c|c|c|c|c|c}
\hline & \multicolumn{2}{|c|}{$\begin{array}{c}\text { Pre-post } \\
\text { measurement }\end{array}$} & \multicolumn{2}{c|}{$\begin{array}{c}\text { Comparison } \\
\text { or control } \\
\text { group }\end{array}$} & \multicolumn{2}{|c|}{$\begin{array}{c}\text { (blind) } \\
\text { randomization }\end{array}$} & \multicolumn{2}{c|}{$\begin{array}{c}\text { Number of } \\
\text { participants }\end{array}$} & \multicolumn{2}{|c|}{$\begin{array}{c}\text { Valid and reliable } \\
\text { measurements }\end{array}$} \\
\hline & Yes & No & Yes & No & Yes & No & N & Yes & No \\
\hline$[74]$ & $\mathrm{X}$ & & $\mathrm{X} 2$ & $\mathrm{X} 1$ & $\mathrm{X} 2$ & $\mathrm{X} 1$ & $\mathrm{X} 1=7 \mathrm{X} 2=16$ & $\mathrm{X}$ & $\mathrm{X}$ \\
\hline$[75]$ & & $\mathrm{X}$ & & $\mathrm{X}$ & & $\mathrm{X}$ & $19 \& 7$ & & $\mathrm{X}$ \\
\hline
\end{tabular}




\begin{tabular}{r|c|c|c|c|c|c|c|c|c}
\hline$[76]$ & $\mathrm{X}$ & $\mathrm{X}$ & & $\mathrm{X}$ & & $\mathrm{X}$ & 1 & $\mathrm{X}$ & $\mathrm{X}$ \\
\hline$[77]$ & $\mathrm{X}$ & & & $\mathrm{X}$ & & $\mathrm{X}$ & 19 & $\mathrm{X}$ & \\
\hline$[81]$ & $\mathrm{X}$ & & $\mathrm{X}$ & & & $\mathrm{X}$ & 115 & $\mathrm{X}$ & $\mathrm{X}$ \\
\hline$[82]$ & & $\mathrm{X}$ & & $\mathrm{X}$ & & $\mathrm{X}$ & 1 & & $\mathrm{X}$ \\
\hline$[83]$ & $\mathrm{X}$ & $\mathrm{X}$ & & $\mathrm{X}$ & & $\mathrm{X}$ & 6 & & $\mathrm{X}$ \\
\hline$[84]$ & $\mathrm{X}$ & $\mathrm{X}$ & & $\mathrm{X}$ & & $\mathrm{X}$ & 8 & $\mathrm{X}$ & $\mathrm{X}$ \\
\hline$[85]$ & & $\mathrm{X}$ & & $\mathrm{X}$ & & $\mathrm{X}$ & 7 & $\mathrm{X}$ & $\mathrm{X}$ \\
\hline$[86]$ & $\mathrm{X}$ & & $\mathrm{X}$ & & $\mathrm{X}$ & & 18 & $\mathrm{X}$ & $\mathrm{X}$ \\
\hline$[88]$ & $\mathrm{X}$ & & & $\mathrm{X}$ & & $\mathrm{X}$ & $7 \& 1$ & $\mathrm{X}$ & \\
\hline$[87]$ & $\mathrm{X}$ & & & $\mathrm{X}$ & & $\mathrm{X}$ & $3 \& 1$ & $\mathrm{X}$ & $\mathrm{X}$ \\
\hline
\end{tabular}

Note: X1 is study $1, X 2$ is study 2.

Studies that involved stakeholders in Product Design- and Tailoring Phase had some methodological limitations. The studies were effective with regard to various outcomes measurements. For example, end-users had positive experiences while interacting with the prototype game, e.g., that the prototype was appealing but also had some improvements for the design [75], or that the product was easy to use by the end-users, who also experienced a higher perceived wellbeing [76]. Studies with a control condition, showed improvements in physical health in the experimental condition on physical health, for example, a significant increase in steps per week, but also an increase in weight, BMI and percentage body fat in both experimental and control condition [81], and an improved medication adherence accuracy from $43 \%$ to $56 \%$ in end-users interested in games [86]. A paper that involved two studies reported significant improvements in the upper limb motor function in both studies, as well as improvements in global function in the first study [74]. A study where end-users participated in all study conditions, with different tailoring algorithms, reported that seven of the eight participants could interact with the product, of which six reached the recommended energy expenditure levels, and that the algorithms influenced scores and experiences [84]. Other studies found that the BMI decreased for overweight/obese participants, increased in an underweight participant, and was maintained in healthy participants [77] and that tailoring game-levels to the abilities and performance positively affected body movements during therapy [85]. End-users connected with their avatar (it represented them in performance), and this had (in)significant positive effects on upper-limb stroke rehabilitation [87]. Studies that involved participants with ASD found some engagement with a robot through interaction flow and self-initiation behavior, but with room for improvement [82], and more social engagement and less playing alone, but only when interacting with a robot [83]. Lastly, five out of seven active duty soldiers and one veteran with PTSS were successfully treated by the use of a tailored Virtual Reality, but one did not benefit and two other participants discontinued the therapy [88].

\subsubsection{Other combinations of involving stakeholders in the design Phases}

Table 14. Characteristics to analyse the quality of studies involved in different combination of the Personalized Design Process Phases.

\begin{tabular}{c|c|c|c|c|c|c|c|c|c}
\hline & \multicolumn{2}{|c|}{$\begin{array}{c}\text { Pre-post } \\
\text { measurement }\end{array}$} & \multicolumn{2}{c|}{$\begin{array}{c}\text { Comparison or } \\
\text { control group }\end{array}$} & \multicolumn{2}{c|}{$\begin{array}{c}\text { (blind) } \\
\text { randomization }\end{array}$} & $\begin{array}{c}\text { Number of } \\
\text { participants }\end{array}$ & \multicolumn{2}{|c}{$\begin{array}{c}\text { Valid and reliable } \\
\text { measurements }\end{array}$} \\
\hline & Yes & No & Yes & No & Yes & No & N & Yes & No \\
\hline$[78]$ & $\mathrm{X}$ & $\mathrm{X}$ & $\mathrm{X}$ & & & $\mathrm{X}$ & 18 & $\mathrm{X}$ & $\mathrm{X}$ \\
\hline$[79]$ & $\mathrm{X}$ & & $\mathrm{X}$ & & $\mathrm{X}$ & & 10 & $\mathrm{X}$ & $\mathrm{X}$ \\
\hline$[80]$ & & $\mathrm{X}$ & & $\mathrm{X}$ & & $\mathrm{X}$ & 8 & & $\mathrm{X}$ \\
\hline$[73]$ & $\mathrm{X}$ & & & $\mathrm{X}$ & & $\mathrm{X}$ & 6 & & $\mathrm{X}$ \\
\hline
\end{tabular}


Studies that involved stakeholders in different combination of the PDP phases had some methodological limitations. Studies noted that a product could be more than an icebreaker as it could improve client-patient relationship, but there were also some engagement concerns, according to therapists [80]. Additionally, studies with a control group resulted in enhancements in selective and sustained attention and in overall visual motor abilities, combined with future design requirements [79], but also in design requirements for a product to motivate physical activity in adolescents [78]. Lastly, involving stakeholders in Problem Definition- and Tailoring Phase resulted in effects on playability, where only one user improved control of gestures [73].

\subsubsection{Validating the influence of games involved in Personalized Design Process}

Normally, effects are quantitatively measured by studies that compare an experimental condition with a control group. However, most studies in this literature review were of low methodological quality due to the low number of participants, absence of control group(s) or use of qualitative measurements (e.g., [6]) or non-validated questionnaires. Validated questionnaires that are often used to quantitatively measure the usability or experience of games, are the User Experience Questionnaire [96] and the System Usability Scale [97]. Other validated questionnaires that can measure the health related transfer effect also exist (e.g., Child Depression Rating Scale Revised (CDRS-R) [98], when measuring depression). A minority of 17 studies did include a control group, where end-users only participated in either an experimental or control condition. All found positive results in health related transfer effect, interaction experience and behavior. Of these studies, a majority of 9 studies randomly assigned their participants to either the control or to the experimental group [7, 49, 57, 61, 63, 65, 74, 79, 86].

Generally, the reviewed studies compared experimental groups who received a serious game, that was designed via stakeholder involvement in phases or a phase of the PDP, with groups that received Treatment As Usual without such a game. Other studies compared groups of patients with groups of healthy end-users. Such a comparison can clearly show the health effect of the serious game, but makes it impossible to show the effect of personalization. In order to test the effect of personalization, a comparison should have been made between a product that was developed with stakeholder involvement in the PDP and a product that was developed without stakeholder involvement in the PDP. A majority of the studies with a control group involved stakeholders in the Tailoring Phase [7, 47-49, 54, 57, 61, 63, 65, 68], of which some studied the effect of personalization by comparing tailored vs. non-tailored interventions [7, 49], or a personalized intervention with a likewise non-personalized intervention [47]. Other studies that involved stakeholders in the Tailoring Phase, compared activities with a personalized game product to a standard activity that used a paper and pen method [48], a motivational and tailored learning method with the same learning method but without the motivational and tailored variables [63], and patients with healthy controls [54]. Studies also compared a personalized game with two elected exercises [61], a tailored training with a computer game [65], a training with additional a tailored diet game [68], or did not study or further describe the control group in the paper [57]. Involving stakeholders in the Tailoring Phase seems to have positive effects on the end-users regarding the interaction experiences (e.g., that a product was usable and acceptable [54]), interaction behavior (e.g., reduced agitation and improved mood during an intervention with Alzheimer patients [47]), and health related transfer effects (e.g., significant effects in the intervention group regarding a decrease in fat mass, weight and Body Mass Index, [68]). For a more detailed description of the effects, see the result section 3.3. Because some studies that involved stakeholders in the Tailoring Phase used an experimental setup, that compared a tailored with a non-tailored group, we can only draw conclusions regarding the additional effect of stakeholder involvement in the last phase of the PDP and recommend game designers to involve stakeholders in this phase.

Studies that focused on the health related effect of stakeholder involvement in the Problem Definition- and Product Design Phase of the PDP did not focus on the effect of this personalization. Therefore, it is difficult to conclude that the reported outcomes of the studies were due to stakeholder involvement in these phases. However, some studies did attempt to study the effects of a personalized game. For instance, the two studies that involved stakeholders in both Problem Definition- and Product Design Phase [38, 39], compared participants with autism spectrum disorders (ASD) to participants without ASD or two experiments to see if there was improvement on the outcome measures between the two. These studies found mixed results regarding interaction behavior [38] and positive self-assessed health related transfer outcomes regarding learning about a health aspect [39]. Three studies that involved stakeholders in both Product Design- and Tailoring 
Phase [74, 81, 86], compared an exercising game with exercises in laboratory sessions [81], two groups that had the same app of which one also consisted of a game [86], and therapy alone with the same therapy that also consisted of a personalized game [74]. The games that were designed by stakeholder involvement in both the Product Design- and Tailoring Phase seemed to result in positive [74, 86] and mixed results regarding interaction experience positive [81], positive results regarding interaction behavior (e.g., how the end-user used the product [86]), and health-related transfer effects (e.g., regarding physical functioning and improvement in medication adherence [74, 86]) that were not always fully positive [81]. Only two studies involved stakeholders in all the PDP phases $[78,79]$, and compared a treatment group (that received extra sessions with games) with a control group (who did not receive these), or let groups use different kind of likewise tools. This seemed to result in different but mostly positive interaction experiences [78], and in interaction behavior and health related transfer effects [79]. For a more detailed description of the effects of studies that focused on the effect of these combinations of phases, see the result section 3.3. To study the additional effect of stakeholder involvement across the (other) phases of the PDP, future studies need robust experimental designs that compare personalized versus non-personalized games.

\subsection{Involved game-elements across the PDP}

Table 15. Game-elements in the Personalized Design Phases.

\begin{tabular}{|c|c|c|c|}
\hline \multirow[t]{2}{*}{ Game-element } & \multicolumn{3}{|c|}{ Personalized Design Phases } \\
\hline & $\begin{array}{l}\text { Problem } \\
\text { Definition }\end{array}$ & Product Design & Tailoring \\
\hline Avatar & {$[6,32,38,79]$} & $\begin{array}{c}{[5,38,74,75,77,79} \\
84,87]\end{array}$ & $\begin{array}{c}{[7,44,46,48,49,51-54,60,61} \\
\quad 71,72,74,75,77,79,84,87]\end{array}$ \\
\hline Reward points & {$[40,73,78,79]$} & $\begin{array}{c}{[35,36,40,77-79,81} \\
84-87]\end{array}$ & $\begin{array}{c}{[54-56,60,61,66,70-73,77-79} \\
81,84-87]\end{array}$ \\
\hline Progression/ level & {$\left[\begin{array}{c}{[3,6,32,40,41,73} \\
78,79]\end{array}\right.$} & $\left|\begin{array}{c}{[35,40,41,74,75,77-} \\
79,81,85,87]\end{array}\right|$ & $\begin{array}{c}{[47,48,50,52-59,61-66,68,70} \\
72-75,77-79,81,85,87]\end{array}$ \\
\hline $\begin{array}{c}\text { Social (e.g., leader } \\
\text { boards) }\end{array}$ & {$\left[\begin{array}{c}6,33,38,41,42 \\
78]\end{array}\right.$} & $\begin{array}{c}{[35,38,41,42,76-78} \\
81,86]\end{array}$ & $\begin{array}{c}{[45-47,49,58,60,76-78,81-83} \\
86,87]\end{array}$ \\
\hline $\begin{array}{c}\text { Puzzle, cards, } \\
\text { quiz }\end{array}$ & $\begin{array}{c}{[6,32,33,39,40} \\
42,43]\end{array}$ & $\begin{array}{c}{[4,34-36,39,40,42} \\
43,75,76,81-83]\end{array}$ & {$[45,47,67,68,75,76,81-83]$} \\
\hline $\begin{array}{c}\text { User } \\
\text { assignments in } \\
\text { real life }\end{array}$ & $\begin{array}{c}{[3,6,33,39,42,} \\
78]\end{array}$ & $\begin{array}{c}{[35,37,39,42,78} \\
81]\end{array}$ & {$[50,52,54,57,59,60,62,78,81]$} \\
\hline Others & {$[80]$} & $\begin{array}{c}{[5,38,74,76,80} \\
81,85,86,88]\end{array}$ & $\begin{array}{c}{[50,52,54,55,58,60,61,63,64,} \\
66,67,69-72,74,76,80,81,85, \\
86]\end{array}$ \\
\hline
\end{tabular}

The games that were described in the reviewed papers contained specific game-elements. Game-elements are the elements that are found in games [99], that motivate the player for specific behavior [100]. In papers that focus on personalization, the game-elements have a more abstract role when stakeholders are involved in the Problem Definition Phase, compared to the Product Design- and Tailoring Phase. Generally, game-elements are shaped in the Product Design Phase, of which some studies test these game-elements in the Tailoring Phase. Therefore, game-elements were more "visible", because they are better described and tested in the Product Design- and Tailoring Phase (Table 15).

When stakeholders were involved in the Tailoring Phase, games were used that mostly contained game-elements like "progression", "levels", "reward points" and "avatars". Especially an avatar was often present, since they could be tweaked to the preference or behavior of the user (e.g., let end-users tailor an avatar by giving them freedom to do so [7]). "Points" and "progression" were often combined, because progression or levels can make the points more meaningful: by receiving points, the end-users can see how they progress and eventually reach higher levels. When stakeholders were involved in the Product Design Phase, "progression" and "points" were also often present, but mostly combined with social game-elements, puzzles, and quizzes. In one study, end-users could tweak a game-element themselves, e.g., by adjusting the difficulty level of the 
game [63]. The type of tailoring (e.g., tailoring avatars) was studied in isolation. However, if more game-elements were present in a product, the effects of these game-elements were not measured in isolation, but as a "black box".

\section{Discussion and conclusion}

To our knowledge, this is the first systematic literature review on personalization in games for health. Existing literature from personalized design methods were applied to propose the Personalized Design Process model and to investigate if and how personalization in game design is effective in the context of health. The aim of the PDP-model, which consists of three different design phases in which personalization can be applied, is to provide insights in when personalization can be applied in the design process. The effect of this personalization is aligning a product to the needs and preferences of the end-users $[8,101]$. This can increase the satisfaction with and the value of the product $[102,103]$, the interaction time with the product, and consequently it can positively influence the health related transfer effect. It can be concluded that stakeholders (mostly end-users and domain experts) were often involved in the Tailoring- and Product Design Phase only, and not in the Problem Definition Phase of the PDP. The problem was often pre-defined, for example, by the government or principal, without any check whether it was the correct problem to target [102]. However, it would be preferable to also involve stakeholders in Problem Definition Phase, because this can serve as the basis of the whole design process and provide a more holistic picture of problems and aspects to focus on [104].

If the problem that the game will tackle is not checked with the stakeholders (especially the end-users and domain experts), it is possible that the game is designed for a problem that does not exist or is not possible to improve. This would make it difficult or even impossible to obtain positive results, especially regarding health related transfer effects.

Within the Product Design Phase, we observed different stakeholder involvement, where stakeholders were most often only involved in Embodiment. They could provide comments, suggestions or guidelines, but they could also design products, help designers, and give feedback. It is probable that it would have taken too much time, been too expensive, or not found necessary to also involve stakeholders in short passive tests in Ideation (for example, about the usability) [105]. A majority of the studies only involved stakeholders in the Tailoring Phase. Possibly, this phase is the most important phase for stakeholder feedback in the design process, or perhaps stakeholders can be involved more easily in this phase. Studies often used a Kinect device to give tailored visual feedback to the user about their performance or remaining time, or to tailor the difficulty of the tasks to the end-user input (e.g., in-game performance). The end-user's name was also often used when feedback was given, in order to make the feedback or content more personally relevant and thus more motivating and persuasive for the end-user. End-users actively tailored avatars, which gave them the opportunity to connect to the avatar, as if it was a representation of themselves. Unexpectedly, the objectives, difficulty level or the stimuli of a product were often tailored by others (mostly domain experts). There was an expectation that both a domain expert and end-user would be involved in tailoring these assignments together, e.g., by letting domain experts tailor assignments of which an end-user could choose from, because this would optimally combine the expertise of both the end-users (about preferences and needs) and the domain experts (about theoretical proven assignments or therapy aspects). In addition, it would also give the end-users a sense of choice, which could promote engagement [106].

The studies generally found positive effects on interaction experience, interaction behavior and health related transfer effects. However, because the duration (in time) of the studies was heterogeneous $[45,54,73,83]$ and a majority of the validation methods were not methodologically sound (i.e. a low number of participants or use of measurements that were not valid or reliable), it is hard to compare the results of these studies and to warrant conclusions on the effects of stakeholder involvement across the PDP. Of the 62 studies included in our literature review, a majority (50) had a small study sample $(\mathrm{N}=<50)$. Only 17 studies used a control group, of which nine randomly assigned their participants to either the control or the experimental group $[7,49,57,61,63,65,74$, $79,86]$. Taking these limitations and results into account, it can only be suggested that it is important to involve stakeholders across the Product Design- and Tailoring Phase for a more effective design of games for health. It should be mentioned that involving stakeholders in the PDP can also have some disadvantages. It takes time, money, and effort to let stakeholders participate in the design process [105]. However, if involving stakeholders in the PDP results in better outcomes regarding the experience, behavior and health related transfer effects, this can be seen as more important 
compared to the disadvantages. Balancing the amount of personalization to the expected outcome enhancement should be performed in advance of each game design process.

It is possible that our review strategy did not result in retrieving all available studies on the effects of stakeholder' involvement in the Personalized Design phases, because of the different definitions of personalization that currently exist [107]. We attempted to minimize this, by brainstorming the search strategy and selection of keywords with expert researchers from the field of co-design and personalization, and from psychology and game design. We also proposed a PDP model, which would make it possible to extend the potential of personalization towards a better design in the context of health, and limit the confusion within this field. It should be noted that we did not systematically take user-centered design into account, because according to our definition, it can be part of co-design. It is standard to at least (iteratively) test a product once with possible end-users, and to check whether they understand and can use the product $[8,102]$.

Within the PDP model, we used the general term 'Tailoring' for both User Controlled Customization and Use-Dependent Adaptation. Some studies focused on the technical challenges regarding tailoring, and not on the effects of tailoring. This made it difficult to study the effects of the design outcomes in terms of personalization. It should be noted that in addition to our two tailoring types, we also found another type of tailoring that we termed "Context Dependent Adaptation", where a product is tailored based on the specific context of the end-user. However, with this type, the end-user has no active role in tailoring. Therefore, we did not focus on Context Dependent Adaptation in this review. Examples of this kind of tailoring are studies that personalized a game to the context of end-user (treatment of burn wounds) [108], that let designers make suitable levels for end-user context without influence of end-users or other stakeholders [109], or where tailoring was done based on gamer types, aiming to motivate behavior for each gamer type [110].

In addition to the definition of personalization, the involvement of stakeholders in at least one of the three design phases of the PDP, there may have been confusion regarding the definition of games and gamification and thus some studies could have mistakenly been excluded. Generally, gamification is defined as "the use of game design elements in non-game contexts" [111] and games with a serious aim can be considered as games that do not primarily have an entertainment purpose, but aim towards something "serious", like influencing knowledge [99]. It is interesting that in only one study, end-users could actively tweak the game-elements, e.g., the difficulty level [63]. Some game-elements were commonly involved across the reviewed studies. Points and progression were often combined, e.g., by designing a threshold of a number of points before the user could proceed to the next level, and avatars were often applied to represent the user within the game. However, the effects of these game-elements were not measured in isolation, but as a "black box", making it impossible to measure the influence of separate game-elements. Only the 'way of tailoring', e.g., tailoring the difficulty level to the user or an avatar in different ways, was studied in isolation. It would be preferable to study the separate influence of specific game-elements, to know which specific game-element influences motivation and effect, and how this occurs.

Regarding the different stakeholder involvement when designing games for health, Baranowski et al. (2016) [112] divided the stakeholders into "those who (a) are interested in using games for health to advance their or their organization's agenda, (b) may benefit from playing the games, (c) create games for health for profit, and (d) conduct research on games for health." [112]. The PDP stakeholders can be divided according to these roles. Domain experts are those "interested in using games for health to advance their or their organization's agenda", end-users, family and domain experts are those that "may benefit from playing the games" and designers and experts are those that "create games for health for profit", as well as those who "conduct research on games for health.". We thus agree that involving stakeholders across the creation of a game in the context of health is important, in order to ensure that the game meets their needs, expectations and preferences [112]. However, we recognize a difference between Baranowski's stakeholders. The main difference is that our PDP model also explicitly takes the Problem Definition- and Tailoring Phase into account, and that stakeholders should be involved across all the PDP phases when designing games that aim to positively influence health aspects of end-users.

According to a meta-analysis by DeSmet and colleagues (2014), games should be dynamically tailored to both behavior change needs and socio-demographic information (e.g., tailor the difficulty level to what the user can master). This is already present in our PDP, by involving stakeholders that know about theories of games and behavior change (domain experts and designers) in the whole PDP [113]. We defined 'tailoring based on the performance of the user' as "Use-Dependent Adaptation", and 'tailoring to socio-demographic aspects of the end-user' as "Context Dependent Adaptation". 
In a meta-analysis of 61 studies focusing on stakeholder involvement (more specifically endusers) in serious digital games for healthy lifestyle promotion, DeSmet and colleagues (2016) found other results when end-users were involved in designing games for healthy lifestyle promotion. If they were involved in "participatory design", where end-users were involved as informants, behaviour was changed significantly less effectively than when they were involved in pilot-testing [114]. Participatory design was also related to lower effects on self-efficacy than when end-users were not involved in game design or in pilot-testing. When involved in co-design, stronger health effects were noted when involved in game challenges, but weaker health effects when involved in character and game world creation. This suggests that how stakeholders are involved in personalization can influence the health effects, and that a specific type of stakeholder (end-users) should be equal partners in design instead of being only informants. However, it should be noted that their- and our definition differs: according to DeSmet and colleagues (2016), participatory design represents stakeholder involvement as informants (where they give input and feedback) or as co-designers (where they are equal partners). Co-design thus has a specific role that end-users can have within participatory design. However, according to our definition, participatory design and codesign differ from each other, since co-design puts less weight on the emphasis of user empowerment, as is the case in participatory design [2]. In addition, DeSmet and colleagues (2016) state that users are equal partners in the design process when co-designing. We believe that it is important to give the user the position of 'expert of his/her experience', but that the design responsibility belongs to the design team, since that is their field of expertise. Besides, we also take into account other stakeholder, instead of only end-users as is the case in the study of DeSmet and colleagues (2016).

\subsection{Future work and conclusion}

To conclude, the results of our literature review do not yet allow definite conclusions about whether and when involving stakeholders in the PDP (Problem Definition-, Product Design- and Tailoring Phase) has added value in terms of effect. Therefore, the current motivation to involve stakeholders can be seen as a theoretically driven concept rather than an empirically driven concept. Our findings suggest that stakeholders should be involved in the Tailoring and Product Design Phases. However, a majority of the reviewed studies were hampered by small sample size, lack of control conditions, and other methodological weaknesses. Future studies thus warrant solid evaluation and design strategies for personalization, which may lead to empirically founded conclusions that personalization really enhances behavior, experiences or the health related transfer effect in the context of games for health. However, these future studies should choose their research method with care, because the "golden standard" for experimental validation, a placebo-controlled double-blind study, is complicated using serious games for health as intervention instead of a medical pill you can swallow. Designing products with stakeholder involvement takes a lot of time, and designing control groups in this context is difficult. This is because almost all serious games mix the serious content with the game content and because it is almost impossible create a 'placebo'- or 'control'-game by removing one component without changing the other. Besides, end-users may have different experiences and be differently affected by a game, and participants cannot be blinded [112]. In addition, the 'black-box' of game-elements should be made more visible, by studying the effects of separate and combined game-elements within this context.

In this literature study, we have defined personalization and how it can be applied within the games for health design process. We recommend that future studies not only focus on involving stakeholders in the Product Design- and Tailoring Phase of a PDP, but also to methodologically test whether this stakeholder involvement in the PDP results in better outcomes on experience, behavior and health related transfer effect, by the use of suitable control groups [95].

\section{Acknowledgement}

We would like to thank all the staff of PARC Brijder and TU Delft, who wrote and provided helpful comments during this study. This research is funded by NWO (314-99-102). 


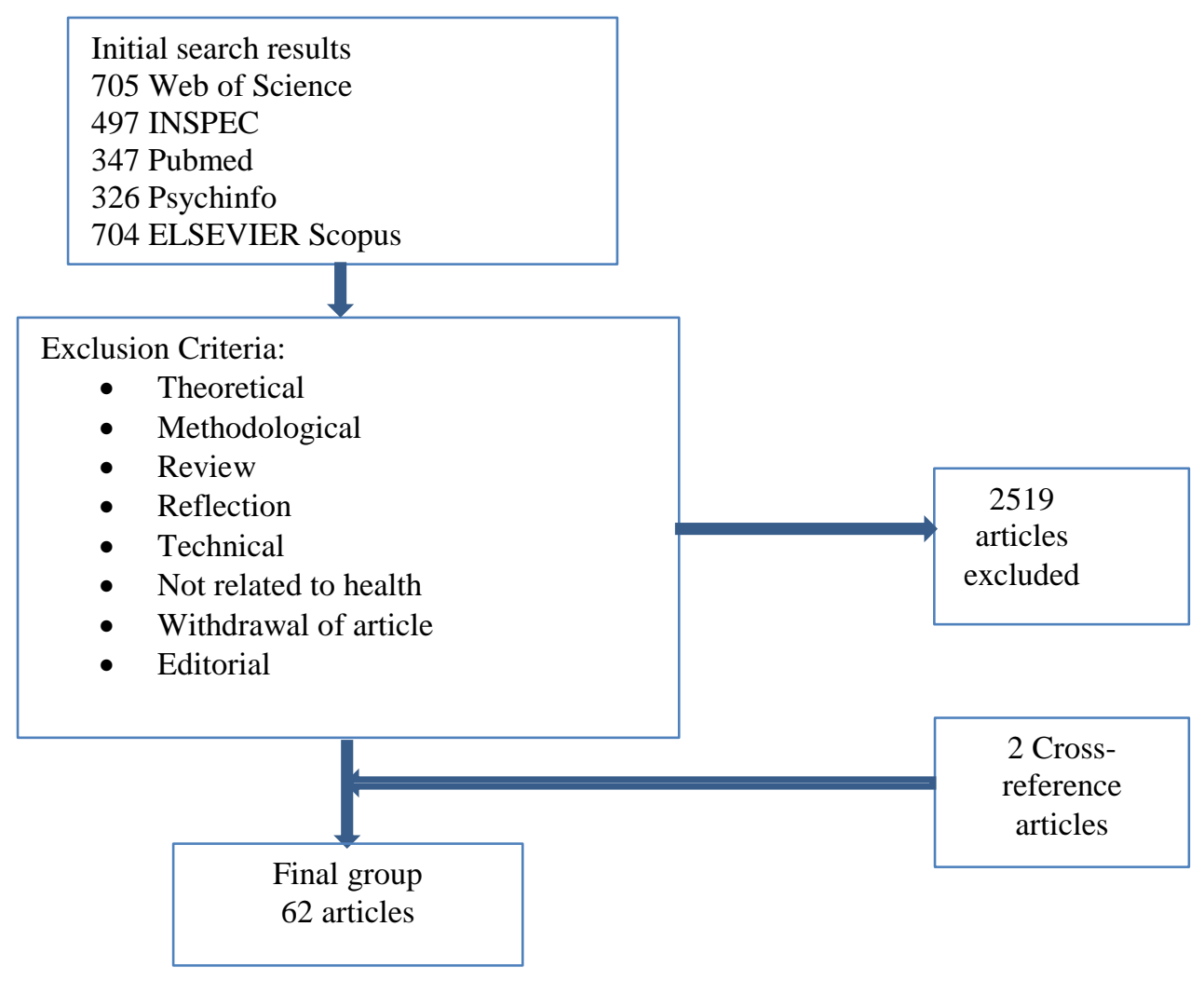

Figure 2. Flow chart of how articles were selected for this study

\section{References}

[1] Teng, C.-I., Customization, immersion satisfaction, and online gamer loyalty. Computers in Human Behavior, Vol., 26, pp. 1547-1554, 2010. http://dx.doi.org/10.1016/j.chb.2010.05.029

[2] Mattelmäki, T., Sleeswijk Visser, F., Lost in Co-X - Interpretations of Co-design and Cocreation. Proceedings of the 4th World Conference on Design Research (IASDR2011): Diversity and Unity, 2011.

[3] Mireya Silva, G. F., Raposo, A., Suplino, M., Exploring Collaboration Patterns in a Multitouch Game to Encourage Social Interaction and Collaboration Among Users with Autism Spectrum Disorder. Computer Supported Cooperative Work (CSCW), Vol., 24, pp. 1-27, 2015. http://dx.doi.org/10.1007/s10606-014-9214-1

[4] Raghupathy, S., Forth, A. L., The HAWK2 program: a computer-based drug prevention intervention for Native American youth. The American Journal of Drug and Alcohol Abuse, Vol., 38, pp. 461-7, 2012. http://dx.doi.org/10.3109/00952990.2012.694531

[5] Holmgård, C., Yannakakis, G. N., Karstoft, K.-I., Andersen, H. S., Stress Detection for PTSD via the StartleMart Game. In proceedings of the Humaine Association Conference on Affective Computing and Intelligent Interaction (ACII), pp. $523-2013$. http://dx.doi.org/10.1109/ACII.2013.92

[6] Glasemann, M., Kanstrup, A. M., Ryberg, T., Design and exploration of a mobile game scenario in a diabetic youth camp. In Proceedings of the IADIS international conference Mobile Learning, pp. 132- 140, Portugal: Porto, 2010. 
[7] Hollingdale, J., Greitemeyer, T., The changing face of aggression: The effect of personalized avatars in a violent video game on levels of aggressive behavior. Journal of Applied Social Psychology, Vol., 43, pp. 1862-1868, 2013. http://dx.doi.org/10.1111/jasp.12148

[8] Sanders E. B.-N., Stappers, P. J., Co-creation and the new landscapes of design. CoDesign: International Journal of CoCreation in Design and the Arts, Vol., 4, pp. 5-18, 2008. http://dx.doi.org/10.1080/15710880701875068

[9] Sanders, E. B.-N., From user-centered to participatory design approaches. In Design and the social sciences: Making connections, Frascara, J., (Ed.) CRC Press, pp. 1-8, 2002. http://dx.doi.org/10.1201/9780203301302.ch1

[10] Profitt, R., Lange, B., User centered design and development of a game for exercise in older adults. International Journal of Technology, Knowledge \& Society, Vol., 8, pp. 95-112, 2012. https://doi.org/10.18848/1832-3669/CGP/v08i05/56330

[11] Frias-Martinez, E., Chen, S. Y., Liu, X., Evaluation of a personalized digital library based on cognitive styles: Adaptivity vs. adaptability. International Journal of Information Management, Vol., 29, pp. 48- 56, 2009. http://dx.doi.org/10.1016/j.ijinfomgt.2008.01.012

[12] Mugge, R., Schoormans, J. P. L., Schifferstein, H. N. J., Incorporating consumers in the design of their own products. The dimensions of product personalisation. CoDesign, Vol., 5, pp. 7997, 2009. http://dx.doi.org/10.1080/15710880802666416

[13] Sundar, S. S., Marathe, S. S., Personalization versus Customization: The Importance of Agency, Privacy, and Power Usage. Human Communication Research, Vol., 36, pp. 298-322, 2010. http://dx.doi.org/10.1111/j.1468-2958.2010.01377.x

[14]Dijkstra, A., The Psychology of Tailoring-Ingredients in Computer-Tailored Persuasion, Social and Personality Psychology Compass, Vol., 2, pp. 765-784, 2008. http://dx.doi.org/10.1111/j.1751-9004.2008.00081.x

[15] Noar, S. M., Harrington, N. G., Aldrich, R. S., The Role of Message Tailoring in the Development of Persuasive Health Communication Messages, Annals of the International Communication Association, Vol., 33, pp. 2009. http://dx.doi.org/10.1080/23808985.2009.11679085

[16]Fjeldsoe, B. S., Marshall, A. L., Miller Y. D., Behavior Change Interventions Delivered by Mobile Telephone Short-Message Service, American Journal of Preventive Medicine, Vol., 36, pp. 165-173, 2009. http://dx.doi.org/10.1016/j.amepre.2008.09.040

[17] Lustria, M. L. A., Cortese, J., Noar, S. M., Glueckauf, R. L., Computer-tailored health interventions delivered over the Web: review and analysis of key components, Patient education and counseling, Vol., 74, pp. 156-173, 2009. http://dx.doi.org/10.1016/j.pec.2008.08.023

[18] Easterbrook, S., Resolving Requirements Conflicts with Computer-Supported Negotiation. In Requirements Engineering: Social and Technical Issues, Jirotka, M., Goguen, J., (Eds.), Academic Press Professional, USA: San Diego, 1994.

[19] van Boeijen, A., Daalhuizen, J., Zijlstra, J., van der Schoor, R., Delft Design Guide: Design Methods, BIS Publishers, Netherlands: Amsterdam, 2013.

[20] Szebeko, D., Tan, L., Co-designing for Society. Australasian Medical Journal, Vol., 3, pp. 580590, 2010. http://dx.doi.org/10.4066/AMJ.2010.378

[21] Visch, V.T., Vegt, N.J.H., Anderiesen, H., van der Kooij, K., 2013. Persuasive Game Design: A model and its definitions. CHI 2013: Workshop Designing Gamification: Creating Gameful and Playful Experiences, 2013.

[22] Baert, V., Gorus, E., Mets, T., Geerts, C., Bautmans, I., Motivators and barriers for physical activity in the oldest old: a systematic review. Ageing research reviews, Vol., 10, pp. 464-474, 2011. http://dx.doi.org/10.1016/j.arr.2011.04.001

[23] Krebs, P., Prochaska, J. O., Rossi, J. S., A meta-analysis of computer-tailored interventions for health behavior change. Preventive medicine, Vol., 51, pp. 214-21, 2010. http://dx.doi.org/10.1016/j.ypmed.2010.06.004

[24] Portnoy, D. B., Scott-Sheldon, L. A., Johnson, B. T., Carey, M. P., Computer-delivered interventions for health promotion and behavioral risk reduction: a meta-analysis of 75 randomized controlled trials, 1988-2007. Preventive medicine, Vol., 47, pp. 3-16, 2008. http://dx.doi.org/10.1016/j.ypmed.2008.02.014

[25]Lieberman, D. A., Bates, C. H., Jiyeon, S., Young Children's Learning With Digital Media. Computers in the Schools, Vol., 26, pp. 271-283, 2009. http://dx.doi.org/10.1080/07380560903360194

[26] Holocher-Ertl, T., Kieslinger, B., Fabian, C.M., Designing for the users or with the users? A participatory design approach for science teaching in schools. Proceedings of the 22nd annual eChallenges Conference, Portugal: Lisbon, 2012. 
[27] Spinuzzi, C., The Methodology of Participatory Design. Technical Communication, Vol., 52, pp. 163- 174, 2005.

[28] Lin, C.-P., Huang, H.-N., Joe, S.-W., Ma, H.-C., Learning the determinants of satisfaction and usage intention of instant messaging. Cyberpsychology \& Behavior, Vol., 11, pp. 262-267, 2008. http://dx.doi.org/10.1089/cpb.2007.0062

[29] Dijkstra, A., The persuasive effects of personalization through: Name mentioning in a smoking cessation message. User Modeling and User-Adapted Interaction, Vol., 24, pp. 393-411, 2014. http://dx.doi.org/10.1007/s11257-014-9147-x

[30] Moss-Morris, R., McCrone, P., Yardley, L., van Kessel, K., Wills, G., Dennison, L., A pilot randomised controlled trial of an Internet-based cognitive behavioural therapy self-management programme (MS Invigor8) for multiple sclerosis fatigue, Behaviour research and therapy, Vol. 50, pp. 415-421, 2012. http://dx.doi.org/10.1016/j.brat.2012.03.001

[31] Merry, S. N., Stasiak, K., Shepherd, M., Frampton, C., Fleming, T.,Lucassen, M. F. G., The effectiveness of SPARX, a computerised self help intervention for adolescents seeking help for depression: randomised controlled non-inferiority trial. BMJ: British Medical Journal, Vol., 344, 2012. http://dx.doi.org/10.1136/bmj.e2598

[32] Crovato, S., Mascarello, G., Pinto, A., Ravarotto, L., Testing a serious game for communicating food risk to young consumers: "A mysterious poisoning". Proceedings of the 5th International Conference on Education and New Learning Technologies: Edulearn13, pp. 283-289, Spain: Barcelona, 2013.

[33] Organista, K. C., Alvarado, N. J., Balblutin-Burnham, A., Worby, P., Martinez, S. R., An Exploratory Study of HIV Prevention with Mexican/Latino Migrant Day Laborers. Journal of HIV/AIDS \& Social Services, Vol., 5, pp. 89-114, 2006. http://dx.doi.org/10.1300/J187v05n02_08

[34] McGaffey, A. L., Abatemarco, D. J., Jewell, I. K., Fidler, S. K., Hughes, K., Fitwits MD ${ }^{\text {TM: An }}$ Office-Based Tool and Games for Conversations about Obesity with 9- to 12-Year-Old Children. Journal of the American Board of Family Medicine, Vol., 24, pp. 768-771, 2011. http://dx.doi.org/10.3122/jabfm.2011.06.100278

[35] Singh, P., Niranjan, I., Using groupwork in the designing and playing of board games in occupational health and safety. Groupwork, Vol., 22, pp. 65-82, 2012. https://doi.org/10.1921/095182412X66218

[36] Cahill, J. M., Health Works: Interactive AIDS education videogames. Computers in Human Services, Vol., 11, pp. 159-176, 1994.

[37] Costa, S., Soares, F., Santos, C., Ferreira, M. J., Moreira, F., et al., An approach to promote social and communication behaviors in children with autism spectrum disorders: Robot based intervention. Proceedings of the 20th IEEE international symposium on robot and human interactive communication: $\quad$ RO-MAN, $\quad$ pp. $101-106, \quad 2011$. http://dx.doi.org/10.1109/ROMAN.2011.6005244

[38] Cobb, S., Beardon, L., Eastgate, R., Glover, T., Kerr, S., et al., Applied virtual environments to support learning of social interaction skills in users with Asperger's Syndrome. Digital Creativity, Vol., 13, pp. 11-22, 2002. http://dx.doi.org/10.1076/digc.13.1.11.3208

[39] Schmitz, B., Klemke, R., Walhout, J., Specht, M., Attuning a mobile simulation game for school children using a design-based research approach. Computers \& Education, Vol., 81, pp. 35-48, 2015. http://dx.doi.org/10.1016/j.compedu.2014.09.001

[40] Alklind Taylor, A.-S., Backlund, P., Engstrom, H., Johannesson, M., Lebram, M., The birth of Elinor: a collaborative development of a game based system for stroke rehabilitation. Proceedings of the 2nd International Conference in Visualisation, pp. 52-60, 2009. http://dx.doi.org/10.1109/VIZ.2009.19

[41] Gotsis, M., Lympouridis, V., Requejo, P., Haubert, L. L., Poulos, I. C., et al., Skyfarer: Design Case Study of a Mixed Reality Rehabilitation Video Game. In Design, User Experience, and Usability. User Experience Design for Diverse Interaction Platforms and Environments. Proceedings of the third International Conference, DUXU: Design, User Experience, and Usability, Vol., 8518, pp. 699-710, 2014. http://dx.doi.org/10.1007/978-3-319-07626-3_66

[42] Nijhof, N., van Hoof, J., van Rijn, H., van Gemert-Pijnen, J.E.W.C., The behavioral outcomes of a technology-supported leisure activity in people with dementia. Technology and Disability, Vol., 24, pp. 263-273, 2013. http://dx.doi.org/10.3233/TAD-140398

[43] McGaffey, A., Hughes, K., Fidler, S. K., D'Amico, F. J., Stalter, M. N., Can Elvis Pretzley and the Fitwits improve knowledge of obesity, nutrition, exercise, and portions in fifth graders? International Journal of Obesity, Vol., 34, pp. 1134-1142, 2010. http://dx.doi.org/10.1038/ijo.2010.58 
[44]Bailey, R., Wise, K., Bolls, P., How avatar customizability affects children's arousal and subjective presence during junk food-sponsored online video games. CyberPsychology \& Behavior, Vol., 12, pp. 277-283, 2009. http://dx.doi.org/10.1089/cpb.2008.0292

[45] Ben-Sasson, A., Lamash, L., Gal, E., To enforce or not to enforce? The use of collaborative interfaces to promote social skills in children with high functioning autism spectrum disorder. Autism, Vol., 17, pp. 608-622, 2013. http://dx.doi.org/10.1177/1362361312451526

[46] González, C. S., Collazos, C., González, J. L., Toledo, P., Blanco, F., The importance of human factors to enhance the user experience in videogames. In Proceedings of Computers in Education (SIIE) 2012 International Symposium, pp. 1-4, 2012.

[47] Cohen, G. D., Two new intergenerational interventions for Alzheimer's disease patients and families. American Journal of Alzheimer's Disease and Other Dementias, Vol., 15, pp. 137-142, 2000. http://dx.doi.org/10.1177/153331750001500304

[48]Hussaan, A. M., Sehaba, K., Adaptive Serious Game for Rehabilitation of Persons with Cognitive Disabilities. In Proceedings of the 13th International Conference on Advanced Learning Technologies, pp. 65-69, 2013. http://dx.doi.org/10.1109/ICALT.2013.25

[49] Kim, Y., Can your avatar improve your health? the impact of avatar customization (Doctoral dissertation). Pennsylvania State University, 2010.

[50] Lund, H. H., Nielsen, C. B., Modularity for modulating exercises and levels - observations from cardiac, stroke, and COLD patients therapy. In Proceedings of the 8th International Conference on Ubiquitous Robots and Ambient Intelligence (URAI), pp. 253 - 258, 2011. http://dx.doi.org/10.1109/URAI.2011.6145971

[51] Chilcott, M., Smith, A., Ageing Well and Learning through Online Immersive Participation Using a Multi-user Web 3D Environment. In Proceedings of the Third International Conference on Games and Virtual Worlds for Serious Applications (VS-GAMES), pp. 70 - 75, 2011. http://dx.doi.org/10.1109/VS-GAMES.2011.16

[52] Albiol-Pérez, S., Forcano-García, M., Muñoz-Tomás, M. T., Manzano-Fernández, P., SolsonaHernández, S., et al., A Novel Virtual Motor Rehabilitation System for Guillain-Barre Syndrome. Two Single Case Studies. Methods of Information in Medicine, Vol., 54, pp. 127134, 2015. http://dx.doi.org/10.3414/ME14-02-0002

[53] Boulanger, C., Boulanger, A., De Greef, L., Kearney, A., Sobel, K., et al., Stroke rehabilitation with a sensing surface. In Proceedings of the SIGCHI Conference on Human Factors in Computing Systems, pp. 1243-1246, 2013. https://doi.org/10.1145/2470654.2466160

[54] Cameirão, M. S., Badia, S. B., Oller, E. D., Verschure, P. F. M. J., Neurorehabilitation using the virtual reality based Rehabilitation Gaming System: methodology, design, psychometrics, usability and validation. Journal of Neuroengineering and Rehabilitation, Vol., 7, 2010. http://dx.doi.org/10.1186/1743-0003-7-48

[55] Kuys, S. S., Hall, K., Peasey, M., Wood, M., Cobb, R., et al., Gaming console exercise and cycle or treadmill exercise provide similar cardiovascular demand in adults with cystic fibrosis: a randomised cross-over trial. Journal of Physiotherapy, Vol., 57, pp. 35-40, 2011. http://dx.doi.org/10.1016/S1836-9553(11)70005-4

[56] Metzger, J. -C., Lambercy, O., Califfi, A., Dinacci, D., Petrillo, C., et al., Assessment-driven selection and adaptation of exercise difficulty in robot-assisted therapy: a pilot study with a hand rehabilitation robot. Journal of Neuroengineering and Rehabilitation, Vol., 112014. http://dx.doi.org/10.1186/1743-0003-11-154

[57] Lyles, C. R., Harris, L. T., Le, T., Flowers, J., Tufano, J., et al., Qualitative Evaluation of a Mobile Phone and Web-Based Collaborative Care Intervention for Patients with Type 2 Diabetes. Diabetes Technology \& Therapeutics, Vol., 13, pp. 563-569, 2011. http://dx.doi.org/10.1089/dia.2010.0200

[58] Wainer, J., Robins, B., Amirabdollahian, F., Dautenhahn, K., Using the humanoid robot KASPAR to autonomously play triadic games and facilitate collaborative play among children with autism. IEEE Transactions on Autonomous Mental Development, Vol., 6, pp. 183-199, 2014. http://dx.doi.org/10.1109/TAMD.2014.2303116

[59] Yuen, H. K., Breland, H. L., Vogtle, L. K., Holthaus, K., Kamen, D. L., et al., The process associated with motivation of a home-based Wii Fit exercise program among sedentary African American women with systemic lupus erythematosus. Disability and Health Journal, Vol., 6, pp. 63-68, 2013. http://dx.doi.org/10.1016/j.dhjo.2012.08.003

[60] Gonzalez-Franco, M., Gilroy, S., Moore, J. O., Empowering patients to perform physical therapy at home. In Proceedings of the 36th Annual International Conference of the IEEE Engineering in Medicine and Biology Society, pp. 6308 - 6311, 2014. http://dx.doi.org/10.1109/EMBC.2014.6945071 
[61] Sparrer, I., Duong Dinh, T. A., Ilgner, J., Westhofen, M., Vestibular rehabilitation using the Nintendo(R) Wii Balance Board -- a user-friendly alternative for central nervous compensation. $\begin{array}{llllll}\text { Acta } & \text { Otolaryngol, } & \text { Vol., } & 133, & \text { pp. }\end{array}$ http://dx.doi.org/10.3109/00016489.2012.732707

[62] Abroms, L. C., Ahuja, M., Kodl, Y., Thaweethai, L., Sims, J., et al., Text2Quit: Results from a pilot test of a personalized, interactive mobile health smoking cessation program. Journal of $\begin{array}{lllll}\text { Health } & \text { Communication, } & \text { Vol., } & \text { 17, }\end{array}$ http://dx.doi.org/10.1080/10810730.2011.649159

[63] Choi, J., Medalia, A., Intrinsic motivation and learning in a schizophrenia spectrum sample. $\begin{array}{lllll}\text { Schizophrenia } \quad \text { Research, } & \text { Vol., } & 118, & \text { pp. } & 12-19,\end{array}$ https://doi.org/10.1016/j.schres.2009.08.001

[64] Gouaïch, A., Hocine, N., Van Dokkum, L., Mottet, D., Digital-pheromone based difficulty adaptation in post-stroke therapeutic games. In Proceedings of the 2nd ACM SIGHIT International Health Informatics Symposium, pp. 5-12, 2012. http://dx.doi.org/10.1145/2110363.2110368

[65]Peretz, C., Korczyn, A. D., Shatil, E., Aharonson, V., Birnboim, S., et al., Computer-based, personalized cognitive training versus classical computer games: A randomized double-blind prospective trial of cognitive stimulation. Neuroepidemiology, Vol., 36, pp. 91-99, 2011. http://dx.doi.org/10.1159/000323950

[66] Plow, M., Finlayson, M., A qualitative study exploring the usability of Nintendo Wii Fit among persons with multiple sclerosis. Occupational Therapy International, Vol., 21, pp. 21-32, 2014. http://dx.doi.org/10.1002/oti.1345

[67] Frutos-Pascual, M., Zapirain, B. G., Zorrilla, A. M., Adaptive Tele-Therapies Based on Serious Games for Health for People with Time-Management and Organisational Problems: Preliminary Results. International Journal of Environmental Research and Public Health, Vol., 11, pp. 749772, 2014. http://dx.doi.org/10.3390/ijerph110100749

[68]Lee, W., Chae, Y. M., Kim, S., Ho, S. H., Choi, I., Evaluation of a mobile phone-based diet game for weight control. Journal of Telemedicine and Telecare, Vol., 16, pp. 270-275, 2010. http://dx.doi.org/10.1258/jtt.2010.090913

[69] Hoque, M. E., Lane, J. K., El Kaliouby, R., Goodwin, M., Picard, R. W., Exploring speech therapy games with children on the autism spectrum. In INTERSPEECH, 10th Annual Conference of the International Speech Communication Association, pp. 1455-1458, 2009.

[70] Octavia, J. R., Coninx, K., Adaptive Personalized Training Games for Individual and Collaborative Rehabilitation of People with Multiple Sclerosis. Biomed Research International, Vol. 2014, 2014. http://dx.doi.org/10.1155/2014/345728

[71] Ustinova, K., Perkins, J., Leonard, W., Hausbeck, C., Virtual reality game-based therapy for treatment of postural and co-ordination abnormalities secondary to TBI: A pilot study. Brain Injury, Vol., 28, pp. 486-495, 2014. http://dx.doi.org/10.3109/02699052.2014.888593

[72] Padilla-Castañeda, M. A., Sotgiu, E., Frisoli, A., Bergamasco, M., Orsini, P., et al., A virtual reality system for robotic-assisted orthopedic rehabilitation of forearm and elbow fractures. In IEEE/RSJ International Conference on Intelligent Robots and Systems, pp. 1506-1511, 2013. http://dx.doi.org/10.1109/IROS.2013.6696548

[73] Bossavit, B., Pina, A., Designing Educational Tools, Based on Body Interaction, for Children with Special Needs Who Present Different Motor Skills. In Proceedings of the 2014 International Conference on Interactive Technologies and Games, pp. 63-70, 2014. https://doi.org/10.1109/itag.2014.16

[74] Shin, J.-H., Ryu, H., Jang, S. H., A task-specific interactive game-based virtual reality rehabilitation system for patients with stroke: a usability test and two clinical experiments. Journal of Neuroengineering and Rehabilitation, Vol., 11, 2014. http://dx.doi.org/10.1186/17430003-11-32

[75] Shepherd, M., Fleming, T., Lucassen, M., Stasiak, K., Lambie, I., et al., The design and relevance of a computerized gamified depression therapy program for indigenous maori adolescents. JMIR Serious Games, Vol., 3, pp. e1, 2015. http://dx.doi.org/10.2196/games.3804

[76] Cornejo, R., Hernandez, D., Tentori, M., Favela, J., An ambient casual game to promote socialization and active ageing. Collaboration and Technoloy, Vol., 8658, pp. 75-88, 2014. http://dx.doi.org/ 10.1007/978-3-319-10166-8_7

[77]Lu, F., Turner, K., Murphy, B., Reducing adolescent obesity with a mobile fitness application: study results of youth age 15 to 17 . In IEEE 15 th International Conference on E-Health, Networking, Application \& Service (Healthcom), pp. $554 \quad$ - 558, 2013. http://dx.doi.org/10.1109/HealthCom.2013.6720738 
[78]Edwards, H. M., McDonald, S., Zhao, T., Humphries, L., Design requirements for persuasive technologies to motivate physical activity in adolescents: A field study. Behaviour \& Information Technology, Vol., $\quad 33, \quad$ pp. $\quad 968-986, \quad 2014$. http://dx.doi.org/10.1080/0144929X.2013.841755

[79] Bartoli, L., Garzotto, F., Gelsomini, M., Oliveto, L., Valoriani, M., Designing and evaluating touchless playful interaction for ASD children. In Proceedings of the 2014 conference on Interaction Design and Children (ICD '14), pp. 17-26, 2014. http://dx.doi.org/10.1145/2593968.2593976

[80] Coyle, D., Doherty, G., Clinical Evaluations and Collaborative Design: Developing new technologies for mental healthcare interventions. In Proceedings of the SIGCHI Conference on Human Factors in Computing Systems (CHI '09), pp. 2051-2060, 2009. http://dx.doi.org/10.1145/1518701.1519013

[81] Johnston, J. D., Massey, A. P., Marker-Hoffman, R. L., Using an alternate reality game to increase physical activity and decrease obesity risk of college students. Journal of Diabetes $\begin{array}{llllll}\text { Science and Technology, } & \text { Vol., }\end{array}$ http://dx.doi.org/10.1177/193229681200600414

[82] Kim, M.-G., Oosterling, I., Lourens, T., Staal, W., Buitelaar, J., et al., Designing robot-assisted Pivotal Response Training in game activity for children with autism. In IEEE International Conference on Systems, Man, and Cybernetics (SMC), pp. 1101-1106, 2014. http://dx.doi.org/10.1109/SMC.2014.6974061

[83] Barakova, E. I., Bajracharya, P., Willemsen, M., Lourens, T., Huskens, B., Long-term LEGO therapy with humanoid robot for children with ASD. Expert Systems, Vol., 32, pp. 698-709, 2015. http://dx.doi.org/10.1111/exsy.12098

[84] Hernandez, H. A., Graham, T. C. N., Fehlings, D., Switzer, L., Ye, Z., et al., Design of an exergaming station for children with cerebral palsy. In Proceedings of the SIGCHI Conference on Human Factors in Computing Systems (CHI '12), pp. 2619-2628, 2012. http://dx.doi.org/10.1145/2207676.2208652

[85] Hocine, N., Gouaïch, A., Cerri, S. A., Mottet, D., Froger, J., et al., Adaptation in serious games for upper-limb rehabilitation: an approach to improve training outcomes. User Modeling and User-Adapted Interaction, Vol., 25, pp. 65-98, 2015. http://dx.doi.org/10.1007/s11257-0159154-6

[86] de Oliveira, R., Cherubini, M., Oliver, N., Acm, MoviPill: Improving Medication Compliance for Elders Using a Mobile Persuasive Social Game. In Proceedings of the 12th ACM international conference on Ubiquitous computing (UbiComp '10), pp. 251-260, 2010. http://dx.doi.org/10.1145/1864349.1864371

[87] Tsekleves, E., Paraskevopoulos, I. T., Warland, A., Kilbride, C., Development and preliminary evaluation of a novel low cost VR-based upper limb stroke rehabilitation platform using Wii technology. Disability and Rehabilitation: Assistive Technology, Vol., 11, pp. 413-422, 2014. http://dx.doi.org/10.3109/17483107.2014.981874

[88] Rizzo, A. A., Graap, K., McLay, R. N., Perlman, K., Rothbaum, B. O., et al., Virtual Iraq: Initial case reports from a VR exposure therapy application for combat-related post traumatic stress $\begin{array}{llllll}\text { disorder. Virtual } & \text { Rehabilitation, } & & \end{array}$ http://dx.doi.org/10.1109/ICVR.2007.4362152

[89] Hekkert, P., Schifferstein, H. N. J., Introducing product experience. In Schifferstein H. N. J., Hekkert, P (Eds.) Product Experience, pp. 1-8, Amsterdam: Elsevier, 2008.

[90] Desmet P., Hekkert, P., Framework of product experience. International Journal of Design, Vol., 1, pp. 57-66, 2007.

[91] Brown, S. J., Lieberman, D. A., Gemeny, B. A., Fan, Y. C., Wilson, D. M., Pasta, D. J., Educational video game for juvenile diabetes: results of a controlled trial. Informatics for Health and Social Care, Vol., 22, pp. 77-89, 1997. http://dx.doi.org/10.3109/14639239709089835

[92] Kato, P. M., Cole, S. W., Bradly, A. S., Pollock, B. H., A video game improves behavioral outcomes in adolescents and young adults with cancer: a randomized trial. Pediatrics, Vol., 122, e305-e317, 2008. http://dx.doi.org/10.1542/peds.2007-3134

[93] McPherson, A. C., Glazebrook, C., Forster, D., James, C., Smyth, A., A randomized, controlled trial of an interactive educational computer package for children with asthma. Pediatrics, Vol., 117, pp. 1046- 1054, 2006. http://dx.doi.org/10.1542/peds.2005-0666

[94] Oinas-Kukkonen, H., A foundation for the study of behavior change support systems. Personal and Ubiquitous Computing, Vol., 17, pp. 1223-1235, 2013. http://dx.doi.org/10.1007/s00779012-0591-5 
[95] van der Kooij, K., Hoogendoorn, E., Spijkerman, R., and Visch V. T., Validation of Games for Behavioral Change: Connecting the Playful and Serious, The International Journal of Serious Games, Vol., 2, pp. 63-75, 2015. http://dx.doi.org/10.17083/ijsg.v2i3.75

[96]Laugwitz, B., Held, T., Schrepp M., Construction and evaluation of a user experience questionnaire: Springer, 2008. http://dx.doi.org/10.1007/978-3-540-89350-9_6

[97] Brooke, J., SUS-A quick and dirty usability scale, Usability evaluation in industry, Vol., 189, pp. 4-7, 1996.

[98] Mayes, T. L., Bernstein, I. H., Haley, C. L., Kennard, B. D., Emslie, G. J. Psychometric properties of the Children's Depression Rating Scale-Revised in adolescents, Journal of child and adolescent psychopharmacology, Vol., 20, pp. 513-516, 2010. http://dx.doi.org/10.1089/cap.2010.0063

[99]Deterding, S., Dixon, D., Khaled, R., Nacke, L., From game design elements to gamefulness: defining "gamification", presented at the Proceedings of the 15th International Academic MindTrek Conference: Envisioning Future Media Environments, Tampere, Finland, 2011. http://dx.doi.org/10.1145/2181037.2181040

[100] Hunicke, R., LeBlanc, M., Zubek, R., MDA: A Formal Approach to Game Design and Game Research. IN Proceedings of the Challenges in Games AI Workshop, Nineteenth National Conference on Artificial Intelligence, pp. 1-5, 2004.

[101] Hu, S. J., Evolving Paradigms of Manufacturing: From Mass Production to Mass Customization and Personalization. Forty Sixth CIRP Conference on Manufacturing Systems, Vol., 7, pp. 3-8, 2013. http://dx.doi.org/10.1016/j.procir.2013.05.002

[102] Steen, M., Manschot, M., Koning, N. D., Benefits of Co-design in Service Design Projects. International Journal of Design, Vol., 5, pp. 53-60, 2011.

[103] Prahalad, C. K., Ramaswamy, V., Co-creation experiences: The next practice in value creation. Journal of Interactive Marketing, Vol., 18, pp. 5-14, 2004. http://dx.doi.org/10.1002/dir.20015

[104] Watts, J., Hirst, M., User participation in the early stages of building design. Design Studies, Vol. 3, pp. 11-18, 1982. http://dx.doi.org/10.1016/0142-694X(82)90074-6

[105] Hoyer, W. D., Chandy, R., Dorotic, M., Krafft, M., Singh, S. S. , Consumer cocreation in new product development. Journal of Service Research, Vol., 13, pp. 283-296, 2010. http://dx.doi.org/10.1177/1094670510375604

[106] Katz, I., Assor, A., When choice motivates and when it does not. Educational Psychology Review, Vol., 19, pp. 429-442, 2007. http://dx.doi.org/10.1007/s10648-006-9027-y

[107] Miceli, G. N., Ricotta, F., Costabile, M., Customizing customization: A conceptual framework for interactive personalization. Journal of Interactive Marketing, Vol., 21, pp. 6-25, 2007. http://dx.doi.org/10.1002/dir.20076

[108] Miller, K., Rodger, S., Kipping, B., Kimble, R. M., A novel technology approach to pain management in children with burns: A prospective randomized controlled trial. Burns, Vol., 37, pp. 395-405, 2011. http://dx.doi.org/10.1016/j.burns.2010.12.008

[109] Malbos, E., Rapee, R. M., Kavakli, M., Creation of interactive virtual environments for exposure therapy through game-level editors: Comparison and tests on presence and anxiety. International Journal of Human-Computer Interaction, Vol., 29, pp. 827-837, 2013. http://dx.doi.org/10.1080/10447318.2013.796438

[110] Orji, R., Vassileva, J., Mandryk, R. L., Modeling the efficacy of persuasive strategies for different gamer types in serious games for health. User Modeling and User-Adapted Interaction, Vol., 24, pp. 453-498, 2014. http://dx.doi.org/10.1007/s11257-014-9149-8

[111] Deterding, S., Sicart, M., Nacke, L., O'Hara, K., Dixon, D., Gamification. using game-design elements in non-gaming contexts. In Proceedings of CHI '11 Extended Abstracts on Human Factors in Computing Systems (CHI EA'11), pp. 2425-2428, 2011. http://dx.doi.org/10.1145/1979742.1979575

[112] Baranowski, T., Blumberg, F., Buday, R., DeSmet, A., Fiellin, L. E., et al., Games for Health for Children-Current Status and Needed Research. Games for health journal, Vol., 5, pp. 1-12, 2016.

[113] DeSmet, A., Van Ryckeghem, D., Compernolle, S., Baranowski, T., Thompson, D., et al. A meta- analysis of serious digital games for healthy lifestyle promotion. Preventive medicine Vol., 69, pp. 95- 107, 2014. http://dx.doi.org/10.1016/j.ypmed.2014.08.026

[114] DeSmet, A., Thompson, D., Baranowski, T., Palmeira, A., Verloigne, M., et al., Is Participatory Design Associated with the Effectiveness of Serious Digital Games for Healthy Lifestyle Promotion? A Meta- Analysis. Journal of Medical Internet Research, Vol., 18, p. e94, 2016. http://dx.doi.org/10.2196/jmir.4444 